\title{
A Direct-Fire Trajectory Model for Supersonic, Transonic, and Subsonic Projectile Flight
}

\author{
by Paul Weinacht
}

ARL-TR-6998

July 2014

Approved for public release; distribution is unlimited. 


\section{NOTICES}

\section{Disclaimers}

The findings in this report are not to be construed as an official Department of the Army position unless so designated by other authorized documents.

Citation of manufacturer's or trade names does not constitute an official endorsement or approval of the use thereof.

Destroy this report when it is no longer needed. Do not return it to the originator. 


\title{
Army Research Laboratory
}

Aberdeen Proving Ground, MD 21005-5066

ARL-TR-6998

July 2014

\section{A Direct-Fire Trajectory Model for Supersonic, Transonic, and Subsonic Projectile Flight}

\author{
Paul Weinacht
}

Weapons and Materials Research Directorate, ARL 


\section{REPORT DOCUMENTATION PAGE}

Public reporting burden for this collection of information is estimated to average 1 hour per response, including the time for reviewing instructions, searching existing data sources, gathering and maintaining the data needed, and completing and reviewing the collection information. Send comments regarding this burden estimate or any other aspect of this collection of information, including suggestions for reducing the burden, to Department of Defense, Washington Headquarters Services, Directorate for Information Operations and Reports (0704-0188), 1215 Jefferson Davis Highway, Suite 1204, Arlington, VA 22202-4302. Respondents should be aware that notwithstanding any other provision of law, no person shall be subject to any penalty for failing to comply with a collection of information if it does not display a currently valid OMB control number.

PLEASE DO NOT RETURN YOUR FORM TO THE ABOVE ADDRESS.

\begin{tabular}{|c|c|c|}
\hline $\begin{array}{l}\text { 1. REPORT DATE (DD-MM-YYYY) } \\
\text { July } 2014\end{array}$ & $\begin{array}{l}\text { 2. REPORT TYPE } \\
\text { Final }\end{array}$ & $\begin{array}{l}\text { 3. DATES COVERED (From - To) } \\
\text { February 2010-December } 2012\end{array}$ \\
\hline \multirow{3}{*}{\multicolumn{2}{|c|}{$\begin{array}{l}\text { 4. TITLE AND SUBTITLE } \\
\text { A Direct-Fire Trajectory Model for Supersonic, Transonic, and Subsonic Projectile } \\
\text { Flight }\end{array}$}} & 5a. CONTRACT NUMBER \\
\hline & & \\
\hline & & 5c. PROGRAM ELEMENT NUMBER \\
\hline \multirow{3}{*}{$\begin{array}{l}\text { 6. AUTHOR(S) } \\
\text { Paul Weinacht }\end{array}$} & & AH80 \\
\hline & & 5e. TASK NUMBER \\
\hline & & 5f. WORK UNIT NUMBER \\
\hline \multicolumn{2}{|c|}{$\begin{array}{l}\text { 7. PERFORMING ORGANIZATION NAME(S) AND ADDRESS(ES) } \\
\text { U.S. Army Research Laboratory } \\
\text { ATTN: RDRL-WML-E } \\
\text { Aberdeen Proving Ground, MD 21005-5066 }\end{array}$} & $\begin{array}{l}\text { 8. PERFORMING ORGANIZATION } \\
\text { REPORT NUMBER } \\
\text { ARL-TR-6998 }\end{array}$ \\
\hline \multirow{2}{*}{\multicolumn{2}{|c|}{ 9. SPONSORING/MONITORING AGENCY NAME(S) AND ADDRESS(ES) }} & 10. SPONSOR/MONITOR'S ACRONYM(S) \\
\hline & & $\begin{array}{l}\text { 11. SPONSOR/MONITOR'S REPORT } \\
\text { NUMBER(S) }\end{array}$ \\
\hline
\end{tabular}

\section{DISTRIBUTION/AVAILABILITY STATEMENT}

Approved for public release; distribution is unlimited.

13. SUPPLEMENTARY NOTES

\section{ABSTRACT}

This report presents a simple but accurate method of determining the trajectory of projectiles that traverse a flight regime that includes supersonic, transonic, and subsonic flight. Closed-form analytical solutions for the important trajectory parameters such as the time of flight, velocity, gravity drop, and wind drift are presented. The method makes use of individual power-law descriptions of the drag variation with Mach number within the supersonic, transonic, and subsonic regimes. The method demonstrates that the free-flight trajectory can be characterized with as few as six parameters: the muzzle velocity, muzzle retardation, a power-law exponent that describes the drag variation in supersonic flight, the transition Mach numbers between supersonic and transonic flight, the transition Mach number between transonic and subsonic flight, and the retardation at the subsonic transition Mach number. The accuracy and simplicity of the method make it very useful for preliminary design or performance assessment studies where rapid prediction of projectile trajectories is desired. Sample results are presented for a 9-mm pistol bullet that traverses supersonic, transonic, and subsonic flight to demonstrate the viability of the method.

15. SUBJECT TERMS

trajectory prediction, flight mechanics, aerodynamics, ballistic calculator, fire control algorithm

\begin{tabular}{|l|l|l|l|l|l|}
\hline \multicolumn{2}{|l|}{ 16. SECURITY CLASSIFICATION OF: } & $\begin{array}{c}\text { 17. LIMITATION } \\
\text { OF ABSTRACT }\end{array}$ & $\begin{array}{l}\text { 18. NUMBER } \\
\text { OF PAGES }\end{array}$ & $\begin{array}{l}\text { 19a. NAME OF RESPONSIBLE PERSON } \\
\text { Paul Weinacht }\end{array}$ \\
\cline { 1 - 2 } $\begin{array}{l}\text { a. REPORT } \\
\text { Unclassified }\end{array}$ & $\begin{array}{l}\text { b. ABSTRACT } \\
\text { Unclassified }\end{array}$ & $\begin{array}{l}\text { c. THIS PAGE } \\
\text { Unclassified }\end{array}$ & UU & 34 & $\begin{array}{l}\text { 19b. TELEPHONE NUMBER (Include area code) } \\
410-306-0800\end{array}$ \\
\hline
\end{tabular}




\section{Contents}

List of Figures $\quad$ iv

List of Tables $\quad$ iv

$\begin{array}{ll}\text { 1. Introduction } & 1\end{array}$

2. Technical Approach $\quad 2$

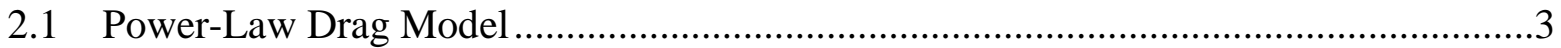

2.2 Analytical Solution Using a Hybrid Supersonic/Transonic/Subsonic Power-Law

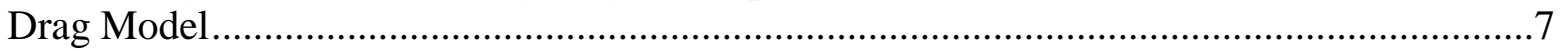

2.2.1 Trajectory Model for Supersonic Portion of Flight .......................................

2.2.2 Transition Between Supersonic and Transonic Flight ....................................9

2.2.3 Trajectory Model for Transonic Portion of Flight.........................................10

2.2.4 Transition Between Transonic and Subsonic Flight.......................................12

2.2.5 Trajectory Model for Subsonic Portion of Flight ...........................................13

2.2.6 Extensions of the Method ........................................................................... 14

$\begin{array}{lr}\text { 3. Results } & 14\end{array}$

$\begin{array}{ll}\text { 4. Conclusions } & 23\end{array}$

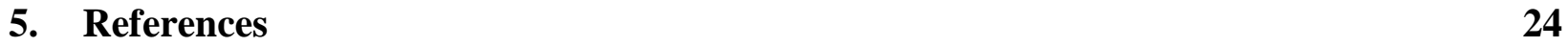

$\begin{array}{ll}\text { Nomenclature } & 25\end{array}$

$\begin{array}{lr}\text { Distribution List } & 28\end{array}$ 


\section{List of Figures}

Figure 1. Supersonic power-law drag coefficient model compared with Aeropack and range data for the M855.

Figure 2. Hybrid supersonic/subsonic power-law drag coefficient model compared with Aeropack and range data for the M855.

Figure 3. Hybrid supersonic/transonic/subsonic power-law drag coefficient model compared with Aeropack and range data for the M855.

Figure 4. Drag coefficient as a function of Mach number: 9-mm pistol bullet.

Figure 5. Velocity as a function of range: $9-\mathrm{mm}$ pistol bullet.

Figure 6. Time of flight vs. range: 9-mm pistol bullet.

Figure 7. Gravity drop vs. range: 9-mm pistol bullet.

Figure 8 . Wind drift vs. range: $9-\mathrm{mm}$ pistol bullet.

Figure 9. Gravity drop velocity vs. range: 9-mm pistol bullet.....

Figure 10. Modeling of drag coefficient as a function of Mach number with different power-law models.

Figure 11. Sensitivity of velocity vs. range to selection of transonic power-law model: 9-mm pistol bullet.

Figure 12. Sensitivity of time of flight vs. range to selection of transonic power-law model:

9-mm pistol bullet.

Figure 13. Sensitivity of gravity drop vs. range to selection of transonic power-law model:

9-mm pistol bullet.

Figure 14. Sensitivity of wind drift vs. range to selection of transonic power-law model:

9-mm pistol bullet.

\section{List of Tables}

Table 1. Parameters for 9-mm ball projectile used in hybrid supersonic/transonic/subsonic model.

Table 2. Parameters for 9-mm ball projectile used in hybrid supersonic/subsonic model. 


\section{Introduction}

Several recent studies have demonstrated there is a need for characterizing the free-flight performance of direct-fire systems including combat rifles, pistols and sniper weapons. For many of these systems, combat rifles for example, the trajectory is characterized by supersonic flight over the useful operational range of the weapon system. Recent studies $(1,2)$ have provided a framework for examining the free-flight trajectory within the constraints of supersonic flight. The basis of this approach is a simple but accurate method for predicting the trajectories for high-velocity direct-fire munitions (1). The method allows the trajectories to be characterized in terms of three parameters: the muzzle velocity, the muzzle retardation (or velocity fall-off), and a parameter defining the shape of the drag curve. The method provides an excellent means of assessing exterior ballistic performance in a conceptual design environment where details of the designs have not been completely defined or in assessment studies where the simple and rapid predictions of the trajectory are desired. Although developed for supersonic flight, the method also allows the prediction of trajectories in subsonic flight where the drag coefficient is constant with Mach number.

While the method of reference 1 has proven very useful, there are some applications where the trajectory involves supersonic flight during early phases of the trajectory and subsonic flight later in the trajectory when the projectile slows due to drag. Examples of these include pistol and long range rifle systems. To address these applications, the method presented in reference 1 was extended so that it could be applied to trajectories with mixed supersonic and subsonic flight (3). A key assumption of the method is that there is an abrupt transition from supersonic to subsonic flight which essentially ignores the effect of the variations in drag in the transonic regime. For many applications, such as long range rifle systems, the duration of the flight in the transonic regime is small compared with the overall length of the flight and the effects on the trajectory are negligible. However, in some cases, such as pistol applications, the projectile may spend a significant portion of the flight in the transonic regime. Although results in reference 3 show a modest effect of an abrupt transition between supersonic and subsonic flight on pistol bullet trajectories, it appears possible to further extend the approach presented in references 1-3 to allow effects of the drag variation in the transonic regime to be included. This is the subject of the current technical report.

In the following sections, the analytical approach for solving the 3 degree-of-freedom (3DOF) trajectory equations is briefly described and benchmarked with numerical predictions of the trajectory of a ball projectile fired from a 9-mm pistol. The 9-mm ball projectile example illustrates a case where the flight includes supersonic, transonic, and subsonic flight over the trajectory. Comparisons are made with results obtained from the current method, the methods presented in references $1-3$, and $4 \mathrm{DOF}$ numerical prediction. The results demonstrate the performance and accuracy of the method. 


\section{Technical Approach}

The flat-fire trajectory of a projectile can be characterized as follows (4):

$$
\begin{gathered}
{\left[\begin{array}{l}
\text { The Complete } \\
\text { Flat Fire Trajectory }
\end{array}\right]=\left[\begin{array}{l}
\text { The Flat Fire } \\
\text { Point MassTrajectory }
\end{array}\right]+\left[\begin{array}{l}
\text { Lateral } \\
\text { Throwoff }
\end{array}\right]+\left[\begin{array}{l}
\text { Aerody namic } \\
\text { Jump }
\end{array}\right]} \\
+\left[\begin{array}{l}
\text { Epicy clic } \\
\text { Swerve }
\end{array}\right]+\left[\begin{array}{l}
\text { Drift }
\end{array}\right]
\end{gathered}
$$

The flat-fire point-mass trajectory accounts for the most dominant characteristics of the trajectory and is most heavily influenced by the mass and drag characteristics of the projectile. It includes such effects as gravity drop and crosswind drift. It is this portion of the trajectory that is the focus of the current conceptual design approach. The aerodynamic jump and lateral throwoff of the projectile produce angular deviations of the flight path from the intended line of flight due to launch disturbances and mass asymmetries within the projectile, respectively. Bias errors associated with these effects are normally removed through the rifle zeroing process. These effects can also produce random errors that contribute to the ammunition dispersion. It is possible to utilize the current method to predict the mean trajectory and statistical methods to address issues associated with ammunition dispersion to determine the pattern of impacts at range. The epicyclic swerve represents fluctuating motions of the projectile about the trajectory due to the angular motion of the projectile. For a stable projectile, these motions are typically small relative to the mean path of the projectile. The drift (or alternatively, spin drift) produces a small horizontal deflection of the projectile due to interaction of the projectile's gyroscopic behavior with the trajectory's curvature due to gravity drop. The deflection is fairly consistent from shot to shot and is typically small compared with crosswind drift.

The flat-fire point-mass trajectory (shown in equations 2-9) can be obtained by solving the point-mass or 3DOF equations, which are obtained from Newton's second law. The flat-fire point-mass equations assume that the transverse aerodynamic forces such as the lift and Magnus forces are small and that the Coriolis acceleration due to the earth's rotation can be neglected. If the total yaw of the projectile is small, the transverse aerodynamic forces can be assumed to be small. Using this approach, the projectile is characterized by its muzzle velocity, mass, and the variation of its drag coefficient with Mach number.

$$
\begin{gathered}
\mathrm{m} \frac{\mathrm{dV}_{\mathrm{x}}}{\mathrm{dt}}=-\frac{1}{2} \rho \mathrm{V}^{2} \mathrm{~S}_{\mathrm{ref}} \mathrm{C}_{\mathrm{D}} \frac{\mathrm{V}_{\mathrm{x}}}{\mathrm{V}} \\
\mathrm{m} \frac{\mathrm{dV} \mathrm{y}}{\mathrm{dt}}=-\frac{1}{2} \rho \mathrm{V}^{2} \mathrm{~S}_{\mathrm{ref}} \mathrm{C}_{\mathrm{D}} \frac{\mathrm{V}_{\mathrm{y}}}{\mathrm{V}}-\mathrm{mg}
\end{gathered}
$$




$$
\begin{aligned}
& \frac{\mathrm{ds}_{\mathrm{x}}}{\mathrm{dt}}=\mathrm{V}_{\mathrm{x}} \\
& \frac{\mathrm{ds} \mathrm{y}_{\mathrm{y}}}{\mathrm{dt}}=\mathrm{V}_{\mathrm{y}}
\end{aligned}
$$

The initial conditions are

$$
\begin{gathered}
\mathrm{V}_{\mathrm{x}}(\mathrm{t}=0)=\mathrm{V}_{0} \cos \theta_{0} \\
\mathrm{~V}_{\mathrm{y}}(\mathrm{t}=0)=\mathrm{V}_{0} \sin \theta_{0} \\
\mathrm{~s}_{\mathrm{x}}(\mathrm{t}=0)=0 \\
\mathrm{~s}_{\mathrm{y}}(\mathrm{t}=0)=0
\end{gathered}
$$

Typically, the integration of the 3DOF equations is performed numerically. However, it is also possible to obtain analytical solutions of the 3DOF equations under the assumption of direct fire using an assumed form of the drag coefficient variation with Mach number (1).

\subsection{Power-Law Drag Model}

The power-law formulation assumes that the drag coefficient variation with Mach number can be modeled as a function of Mach number to a power as shown in equation 10. For constant atmospheric conditions, the sound speed is constant, and the Mach number and velocity are directly proportional. In this case, the drag coefficient varies with Mach number and velocity in the same manner.

$$
\mathrm{C}_{\mathrm{D}} \propto \frac{1}{\mathrm{M}^{\mathrm{n}}} \propto \frac{1}{\mathrm{~V}^{\mathrm{n}}}
$$

Figure 1 shows the variation of the drag coefficient with Mach number for the 5.56-mm M855. The Firing Tables Branch (FTB), U.S. Army Armament Research, Development and Engineering Center (ARDEC), "aeropack" data (5) used to construct firing tables for the round are shown along with aerodynamic spark range data (6). Clearly, the power-law description is not capable of describing the drag variation with Mach number over the complete Mach number regime. However, the drag variation can be modeled with the power-law description in specific regimes. The fit of the FTB aeropack drag coefficient data obtained using the power-law formulation in the supersonic regime is shown in equation 10. The computed exponent for the M855 is 0.53 for the range between Mach 2.8 (muzzle velocity) and Mach 1.1. The power-law fit shows excellent agreement over this Mach number range.

Reference 1 examined the drag coefficient variation of a wide variety of munitions and found that the drag coefficient exponent varied between 0.0 and 1.0 for supersonic flight. This was further confirmed in reference 2 specifically for small-arms ammunition and a correlation 
developed for small-arms ammunition relating the drag coefficient exponent to the aeroballistic form factor. In general, as small-arms projectiles become more blunt and less streamlined, the drag coefficient exponent decreased.

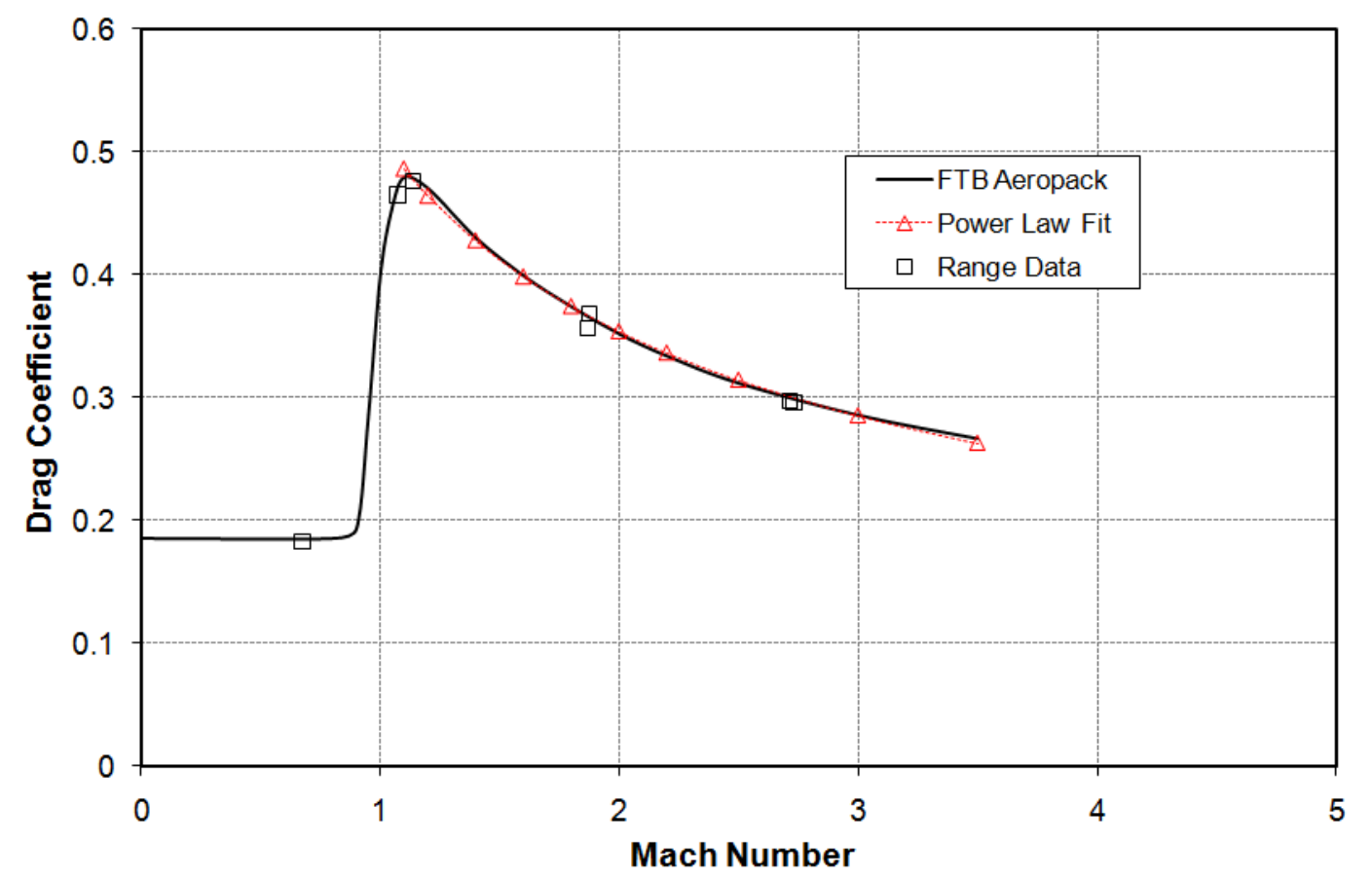

Figure 1. Supersonic power-law drag coefficient model compared with Aeropack and range data for the $\mathrm{M} 855$.

For subsonic flight (nominally $\mathrm{M}<0.8$ ), the projectile typically exhibits a constant drag coefficient with Mach number as shown in figure 1. This type of variation of the drag coefficient can also be modeled with the functional relationship shown in equation 10 where $n=0$. Thus, the drag of a projectile flying in either purely supersonic flight or subsonic flight can be described using a power-law formulation within each regime as described in reference 1.

Reference 3 proposed a drag description that allowed supersonic to subsonic flight to be considered by using a piece-wise description of the supersonic and subsonic drag variation in the supersonic and subsonic regimes with the transonic drag rise represented by an abrupt transition between the supersonic and subsonic regimes as show in figure 2 . This allowed the development of closed-form expressions to compute the trajectory from supersonic through subsonic flight. For many projectiles (for example, projectiles fired from rifles) the projectile traverses the transonic regime over a small distance compared with the length of its overall flight path. For these situations, ignoring the transonic drag variation represents a good assumption, and the results of the model compare favorably with more complete 3DOF predictions that include the effect of the transonic regime. 


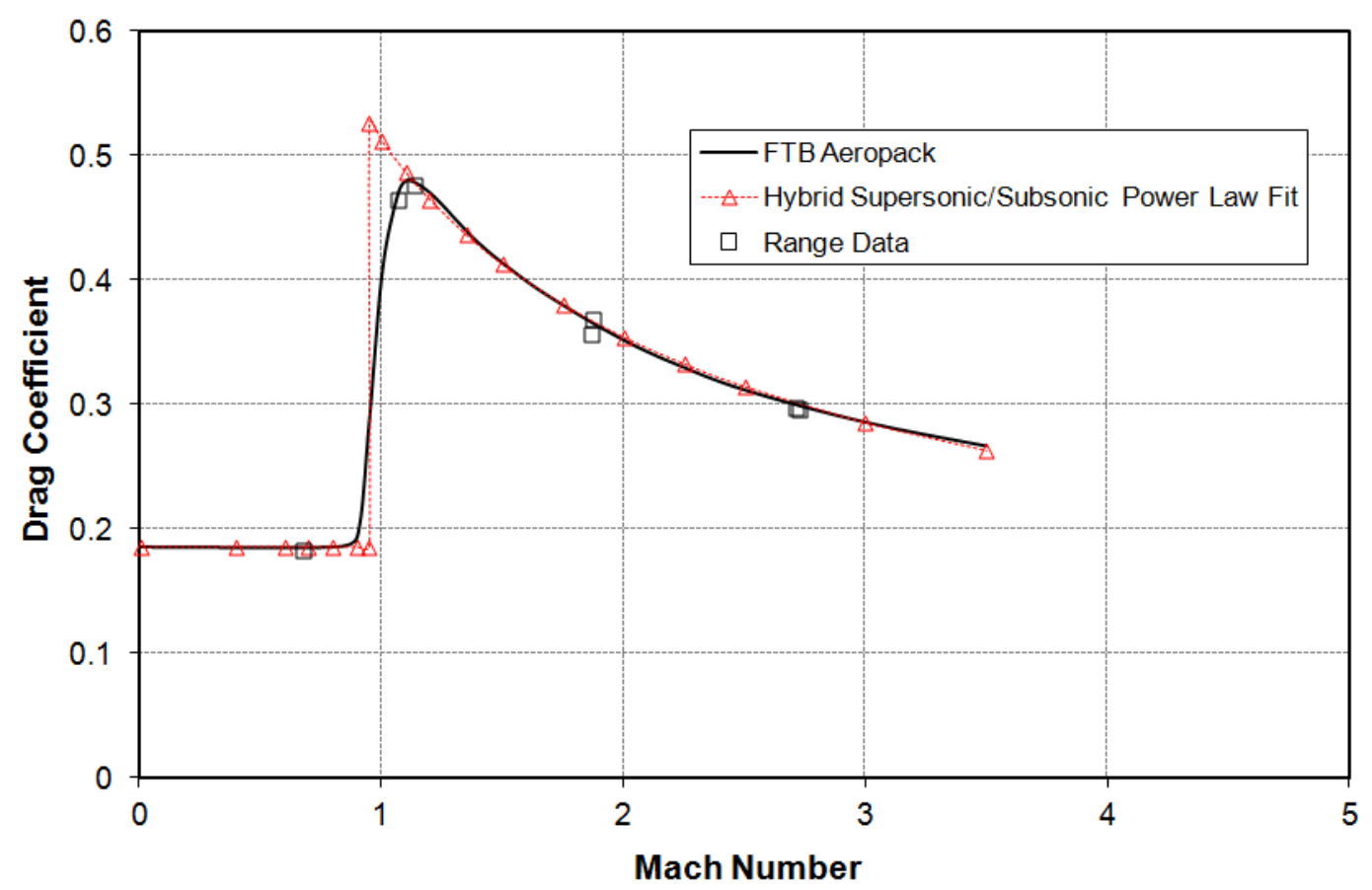

Figure 2. Hybrid supersonic/subsonic power-law drag coefficient model compared with Aeropack and range data for the M855.

There are, however, situations where the transonic regime represents a significant portion of the overall flight. A common example is the flight of a pistol bullet. Here it is desirable to have a model that describes the drag behavior in the transonic regime. It appears that the power-law approach can be adopted to treat the subsonic, transonic, and supersonic regimes with separate power-law drag models. When the transonic drag behavior is treated with a power-law model, it appears to provide a reasonable approximation to the transonic drag rise, although this probably represents more of a curve-fitting technique than a model with a strong physical basis. This power-law representation should allow the development of closed-form solutions similar to those developed in references $1-3$.

The transonic power-law model is shown in equation 11. For constant atmospheric conditions, the sound speed is constant, and the Mach number and velocity are directly proportional. If the upper bound of the velocity of the subsonic regime (and the lower bound of the velocity of the transonic regime) is represented by $\mathrm{V}_{\text {sub }}$ and the upper bound of the velocity of the transonic regime is represented by $\mathrm{V}_{\text {tran }}$ and the drag coefficients at the lower and upper bounds of the transonic regime are $C_{D_{\text {transonic-lower }}}$ and $C_{D_{\text {transonic-upper }}}$, then the drag coefficient in the transonic regime can be expressed as

$$
C_{D}=C_{D_{\text {transonic-upper }}}\left(\frac{M_{\text {tran }}}{M}\right)^{n_{\text {tran }}}=C_{D_{\text {transonic-upper }}}\left(\frac{V_{\text {tran }}}{V}\right)^{n_{\text {tran }}}
$$




$$
\mathrm{n}_{\text {tran }}=-\ln \left(\frac{\mathrm{C}_{\mathrm{D}_{\text {transonic-lower }}}}{\mathrm{C}_{\mathrm{D}_{\text {transonic-upper }}}}\right) / \ln \left(\frac{\mathrm{M}_{\text {sub }}}{\mathrm{M}_{\text {tran }}}\right)
$$

There is no requirement for the drag curve to be continuous with the Mach number from the subsonic to the supersonic regimes. In other words, $\mathrm{C}_{\mathrm{D}_{\text {transonic-lower }}}$ does not have to be equal to the subsonic drag, and $\mathrm{C}_{\mathrm{D}_{\text {transonic-upper }}}$ does not have to be equal to the supersonic drag at the lower end of the supersonic regime.

If there is a discontinuity in the drag curve at both the upper and lower bounds of the transonic regime, there are eight parameters required to define the entire drag curve:

- A reference velocity in the supersonic regime (typically taken as the muzzle velocity) and a reference drag coefficient at the reference velocity

- The drag coefficient exponent in the supersonic regime

- The Mach number (or velocity) at the boundary between the transonic regime and the supersonic regime

- $\mathrm{M}_{\text {tran }}$

- The Mach number (or velocity) at the boundary between the subsonic and transonic regime

- $\quad \mathrm{M}_{\mathrm{sub}}$

- The two drag coefficients at bounds of the transonic regime

- The subsonic drag coefficient

If the drag curve is assumed to be continuous, the number of parameters required to describe the drag curve is reduced to six. Here, the two drag coefficients at the bounds of the transonic regime can be eliminated as parameters, since the drag coefficient at the lower bound of the transonic regime is equal to the subsonic drag coefficient and the drag coefficient at the upper bound of the transonic regime can be computed from the supersonic power-law model. From a practical standpoint, the assumption that the drag curve is continuous may be the preferred approach in most cases and is consistent with implementations made in most other trajectory models. Also, incorporating the transonic drag rise adds one additional parameter, for a total of six parameters (if the drag curve is assumed continuous), to define the drag curve compared to the five parameters required for the hybrid supersonic/subsonic model of reference 3.

Figure 3 shows an example of the hybrid supersonic/transonic/subsonic power-law drag model for the M855 projectile compared with FTB, ARDEC "aeropack" data (5) and aerodynamic spark range range data. The computed power-law exponent for the M855 is 0.53 for the 
supersonic regime and a constant drag coefficient $(\mathrm{n}=0)$ is used in the subsonic regime as discussed previously. When equation 11 is used and a continuous drag curve is assumed, $M_{\text {sub }}=0.9$, and $M_{\text {tran }}=1.05$, a drag coefficient exponent of $n_{\text {tran }}=-3.63$ was computed for the transonic regime. The power-law model of drag curve represents the ARDEC aeropack fairly well.

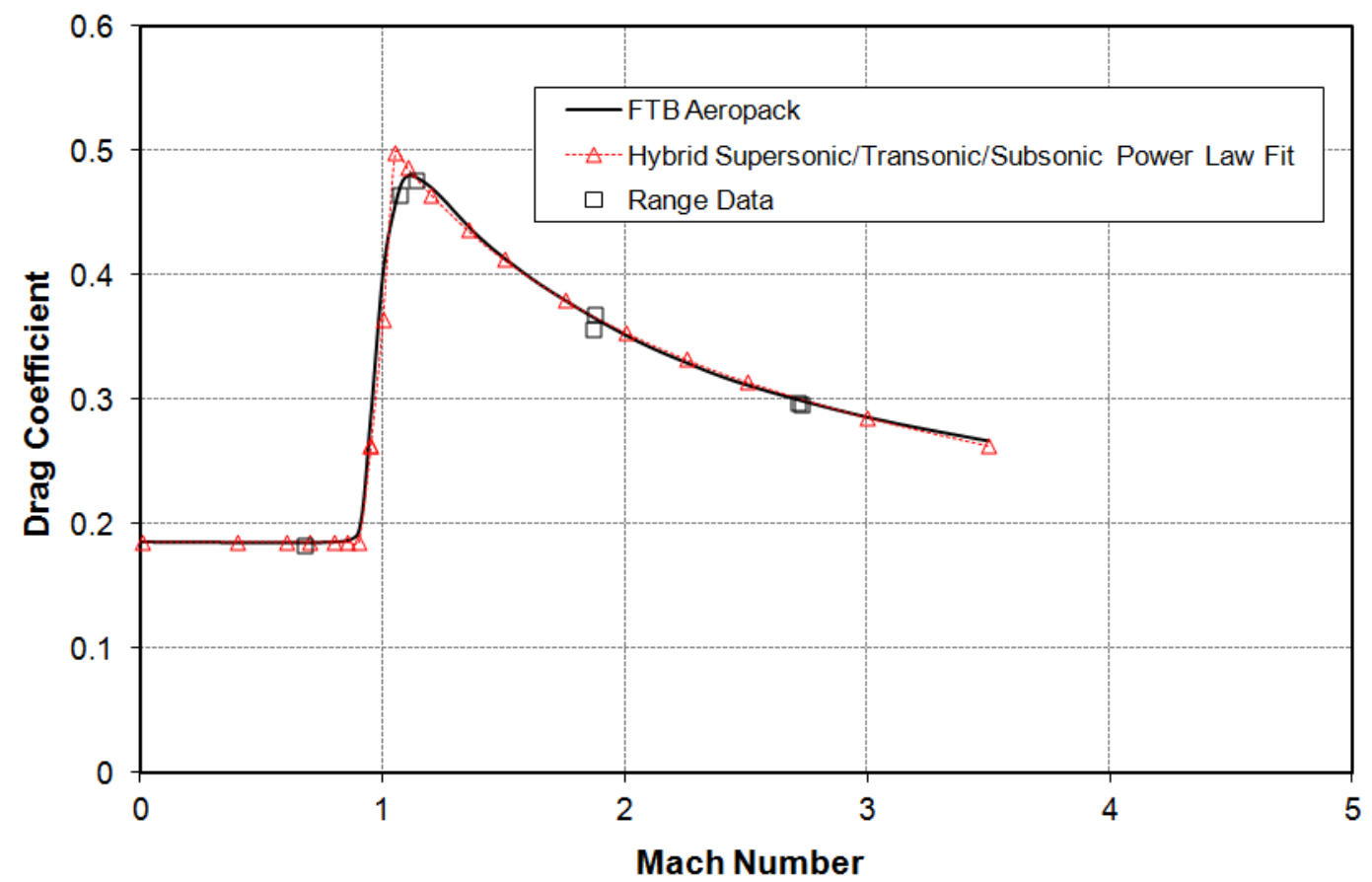

Figure 3. Hybrid supersonic/transonic/subsonic power-law drag coefficient model compared with Aeropack and range data for the M855.

\subsection{Analytical Solution Using a Hybrid Supersonic/Transonic/Subsonic Power-Law Drag Model}

For mixed supersonic/transonic/subsonic flight, the initial supersonic portion of the flight can be modeled using the analytical approach shown in reference 1 . The analytical solutions are obtained using two main approximations. First, the gravity drop contributes little to total velocity during the flight. This assumption implies that the vertical displacement along the trajectory is small (direct-fire) and allows the 3DOF equations to be decoupled.

$$
\mathrm{V}=\sqrt{\mathrm{V}_{\mathrm{x}}^{2}+\mathrm{V}_{\mathrm{y}}^{2}} \cong \overline{\mathrm{V}}
$$

Second, the vertical and lateral displacements are small in relation to the downrange displacement and the total displacement along the trajectory (or slant-range) is nearly equal to the downrange displacement. This second assumption allows the downrange displacement to be treated as one of the primary independent variables. 


$$
\mathrm{s}=\sqrt{\mathrm{s}_{\mathrm{x}}^{2}+\mathrm{s}_{\mathrm{y}}^{2}+\mathrm{s}_{\mathrm{z}}^{2}} \cong \mathrm{s}_{\mathrm{x}}
$$

\subsubsection{Trajectory Model for Supersonic Portion of Flight}

Reference 1 shows that by using the power-law approach, an analytical solution for the supersonic portion of flight can be obtained resulting in closed-form equations for the dependent variables characterizing the projectile trajectory. These include the velocity $\mathrm{V}$, time of flight $\mathrm{t}$, gravity drop $\mathrm{s}_{\mathrm{g} \text {-drop }}$, vertical displacement of the projectile along the trajectory $\mathrm{s}_{\mathrm{y}}$, and vertical deflection due to crosswind $s_{z}$ as a function of range $s_{x}$. Equations 15-22 present closed-formed solutions for these dependent variables for a variable drag coefficient exponent $(n \neq 0,1,2)$ as presented in reference 1. (Special case solutions for $\mathrm{n}=0,1$ or 2 are also shown in reference 1. Inclusion of these solutions in the present analysis is straightforward.) The displacement due to wind drift in equation 19 is a generalized formula based on the integration of the 3DOF equations shown in McCoy (7).

$$
\begin{aligned}
& \mathrm{V}_{\mathrm{x}}=\overline{\mathrm{V}} \cos \theta_{0} \\
& \mathrm{~V}_{\mathrm{y}}=\overline{\mathrm{V}} \sin \theta_{0}+\mathrm{V}_{\mathrm{g}-\mathrm{drop}} \\
& \overline{\mathrm{V}}=\mathrm{V}_{0}\left\{1+\mathrm{n}\left(\frac{\mathrm{dV}}{\mathrm{ds}}\right)_{0} \frac{\mathrm{s}_{\mathrm{x}}}{\mathrm{V}_{0}}\right\}^{\frac{1}{\mathrm{n}}} \\
& \mathrm{s}_{\mathrm{y}}=\mathrm{s}_{\mathrm{x}} \tan \theta_{0}+\mathrm{s}_{\mathrm{g}-\mathrm{drop}} \\
& \mathrm{s}_{\mathrm{z}}=\mathrm{w}_{\mathrm{z}}\left[\mathrm{t}-\frac{\mathrm{s}_{\mathrm{x}}}{\mathrm{V}_{0}}\right] \\
& \mathrm{t}=\frac{1}{(\mathrm{n}-1)\left(\frac{\mathrm{dV}}{\mathrm{ds}}\right)_{0}}\left[\left\{1+\mathrm{n}\left(\frac{\mathrm{dV}}{\mathrm{ds}}\right)_{0} \frac{\mathrm{s}_{\mathrm{x}}}{\mathrm{V}_{0}}\right\}^{1-\frac{1}{\mathrm{n}}}-1\right]
\end{aligned}
$$

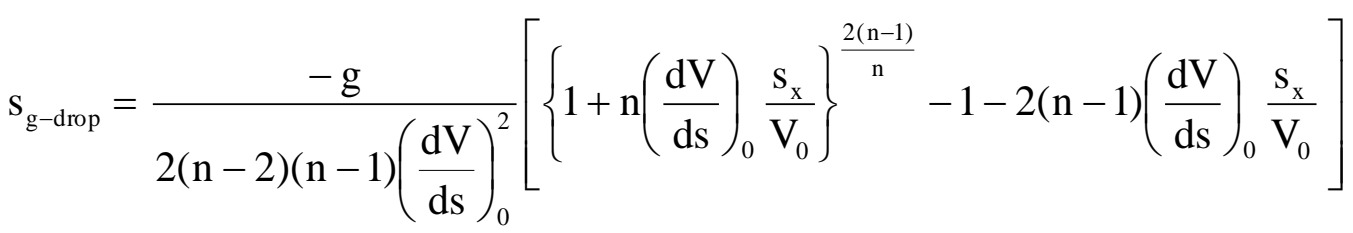




$$
\begin{array}{ccc}
\mathrm{V}_{\mathrm{g}-\mathrm{drop}}=\frac{-\mathrm{g}}{(\mathrm{n}-2)\left(\frac{\mathrm{dV}}{\mathrm{ds}}\right)_{0}}\left[\left\{1+\mathrm{n}\left(\frac{\mathrm{dV}}{\mathrm{ds}}\right)_{0} \frac{\mathrm{s}_{\mathrm{x}}}{\mathrm{V}_{0}}\right\}^{\frac{\mathrm{n}-1}{\mathrm{n}}}\right. & \\
\left.-\left\{1+\mathrm{n}\left(\frac{\mathrm{dV}}{\mathrm{ds}}\right)_{0} \frac{\mathrm{s}_{\mathrm{x}}}{\mathrm{V}_{0}}\right\}^{\frac{1}{\mathrm{n}}}\right] & \mathrm{n} \neq 0,1,2
\end{array}
$$

In the supersonic regime, these trajectory characteristics are functions of only three primary variables, the projectile's muzzle velocity $\mathrm{V}_{0}$, muzzle retardation $\left(\frac{\mathrm{dV}}{\mathrm{ds}}\right)_{0}$, and the exponent defining the shape of the drag curve, $\mathrm{n}$. The trajectory is also a function of two independent parameters, the gravitational constant $\mathrm{g}$, and the crosswind velocity $\mathrm{w}_{\mathrm{z}}$. The gun elevation angle $\theta_{0}$ also appears in equations 15,16 , and 18 and can be treated as another independent parameter. However, the gun elevation angle $\theta_{0}$ required to hit a target at range can be related to the three primary variables: the muzzle velocity, muzzle retardation, and drag coefficient exponent. In this regard, the gun elevation angle itself can be treated as a dependent variable. The muzzle velocity and muzzle retardation have the strongest influence on the trajectory, and the exponent defining the shape of the drag curve can be shown to be a higher-order effect whose influence is less important that the first two variables, particularly at shorter ranges.

The muzzle retardation is dependent on the projectile mass and muzzle drag coefficient as shown in equation 23 .

$$
\left(\frac{\mathrm{dV}}{\mathrm{ds}}\right)_{0}=-\left.\frac{1}{2 \mathrm{~m}} \rho \mathrm{V}_{0} \mathrm{~S}_{\mathrm{ref}} \mathrm{C}_{\mathrm{D}}\right|_{\mathrm{V}_{0}}
$$

Thus, the effect of both projectile mass and muzzle drag coefficient on the trajectory are represented by a single parameter, the muzzle retardation.

\subsubsection{Transition Between Supersonic and Transonic Flight}

For the composite supersonic-transonic-subsonic model, equations 15-22 are valid until the projectile reaches the transition Mach number between supersonic and transonic flight. The transition velocity is determined from the Mach number as shown in equation 24.

$$
\mathrm{V}_{\text {tran }}=\mathrm{a}_{\infty} \mathrm{M}_{\text {tran }}
$$

When equations 17 and 20-22 are used, the range, time of flight, gravity drop, and gravity drop velocity where the transition occurs between the supersonic and transonic flight can be determined. 


$$
\begin{aligned}
& \mathrm{s}_{\mathrm{x}_{\text {tran }}}=\frac{\mathrm{V}_{0}}{\left(\frac{\mathrm{dV}}{\mathrm{ds}}\right)_{0} \mathrm{n}}\left\{\left(\frac{\mathrm{V}_{\text {tran }}}{\mathrm{V}_{0}}\right)^{\mathrm{n}}-1\right\} \\
& \mathrm{t}_{\text {tran }}=\frac{1}{(\mathrm{n}-1)\left(\frac{\mathrm{dV}}{\mathrm{ds}}\right)_{0}}\left[\left\{1+\mathrm{n}\left(\frac{\mathrm{dV}}{\mathrm{ds}}\right)_{0} \frac{\mathrm{s}_{\mathrm{xtran}}}{\mathrm{V}_{0}}\right\}^{1-\frac{1}{\mathrm{n}}}-1\right] \\
& \mathrm{s}_{\mathrm{g}-\mathrm{drop}_{\text {tran }}}=\frac{-\mathrm{g}}{2(\mathrm{n}-2)(\mathrm{n}-1)\left(\frac{\mathrm{dV}}{\mathrm{ds}}\right)_{0}^{2}}\left[\left\{1+\mathrm{n}\left(\frac{\mathrm{dV}}{\mathrm{ds}}\right)_{0} \frac{\mathrm{s}_{\mathrm{x}_{\text {tran }}}}{\mathrm{V}_{0}}\right\}^{\frac{2(\mathrm{n}-1)}{\mathrm{n}}}-1-2(\mathrm{n}-1)\left(\frac{\mathrm{dV}}{\mathrm{ds}}\right)_{0} \frac{\mathrm{s}_{\mathrm{x}_{\text {tran }}}}{\mathrm{V}_{0}}\right] \\
& \mathrm{V}_{\mathrm{g}-\mathrm{drop}_{\text {tran }}}=\frac{-\mathrm{g}}{(\mathrm{n}-2)\left(\frac{\mathrm{dV}}{\mathrm{ds}}\right)_{0}}\left[\left\{1+\mathrm{n}\left(\frac{\mathrm{dV}}{\mathrm{ds}}\right)_{0} \frac{\mathrm{s}_{\mathrm{x}_{\text {tran }}}}{\mathrm{V}_{0}}\right\}^{\frac{\mathrm{n}-1}{\mathrm{n}}}\right. \\
& \left.-\left\{1+\mathrm{n}\left(\frac{\mathrm{dV}}{\mathrm{ds}}\right)_{0} \frac{\left.\mathrm{s}_{\mathrm{x}_{\text {tran }}}\right)}{\mathrm{V}_{0}}\right\}^{\frac{1}{\mathrm{n}}}\right]
\end{aligned}
$$

\subsubsection{Trajectory Model for Transonic Portion of Flight}

When equations 25-28 are used as initial conditions, the governing 3DOF equations can be integrated to determine the trajectory in the transonic portion of flight. The solution has a similar form to the solution for the supersonic portion of flight as shown in equations 29-32. As discussed previously, a different power-law exponent is used to describe the drag behavior in the transonic regime.

$$
\begin{gathered}
\mathrm{V}_{\mathrm{x}}=\overline{\mathrm{V}} \cos \theta_{0} \\
\mathrm{~V}_{\mathrm{y}}=\overline{\mathrm{V}} \sin \theta_{0}+\mathrm{V}_{\mathrm{g}-\mathrm{drop}} \\
\mathrm{s}_{\mathrm{y}}=\mathrm{s}_{\mathrm{x}} \tan \theta_{0}+\mathrm{s}_{\mathrm{g}-\text { drop }} \\
\mathrm{s}_{\mathrm{z}}=\mathrm{w}_{\mathrm{z}}\left[\mathrm{t}-\frac{\mathrm{s}_{\mathrm{x}}}{\mathrm{V}_{0}}\right]
\end{gathered}
$$

where 


$$
\begin{aligned}
& \bar{V}=V_{\text {tran }}\left\{1+n_{\text {tran }}\left(\frac{d V}{d s}\right)_{\operatorname{tran}} \frac{s_{x}-s_{x_{\text {tran }}}}{V_{\text {tran }}}\right\}^{\frac{1}{n_{\text {tran }}}} \\
& \mathrm{t}=\frac{1}{\left(\mathrm{n}_{\text {tran }}-1\right)\left(\frac{\mathrm{dV}}{\mathrm{ds}}\right)_{\operatorname{tran}}}\left[\left\{1+\mathrm{n}_{\operatorname{tran}}\left(\frac{\mathrm{dV}}{\mathrm{ds}}\right)_{\operatorname{tran}} \frac{\left(\mathrm{s}_{\mathrm{x}}-\mathrm{s}_{\mathrm{x}_{\text {tran }}}\right)}{\mathrm{V}_{\text {tran }}}\right\}^{1-\frac{1}{\mathrm{n}_{\text {tran }}}}-1\right]+\mathrm{t}_{\text {tran }} \\
& \mathrm{s}_{\mathrm{g}-\mathrm{drop}}=\frac{-\mathrm{g}}{2\left(\mathrm{n}_{\text {tran }}-2\right)\left(\mathrm{n}_{\text {tran }}-1\right)\left(\frac{\mathrm{dV}}{\mathrm{ds}}\right)_{\text {tran }}^{2}}\left[\left\{1+\mathrm{n}_{\text {tran }}\left(\frac{\mathrm{dV}}{\mathrm{ds}}\right)_{\operatorname{tran}} \frac{\left(\mathrm{s}_{\mathrm{x}}-\mathrm{s}_{\mathrm{x}_{\text {tran }}}\right)}{\mathrm{V}_{\text {tran }}}\right\}^{\frac{2\left(\mathrm{n}_{\text {tran }}-1\right)}{\mathrm{n}_{\text {tran }}}}\right. \\
& \left.-1-2\left(\mathrm{n}_{\text {tran }}-1\right)\left(\frac{\mathrm{dV}}{\mathrm{ds}}\right)_{\operatorname{tran}} \frac{\left(\mathrm{s}_{\mathrm{x}}-\mathrm{s}_{\mathrm{x}_{\text {tran }}}\right)}{\mathrm{V}_{\text {tran }}}\right] \\
& +\frac{\mathrm{V}_{\mathrm{g}-\text { droptran }_{\text {tran }}}}{\mathrm{V}_{\text {tran }}}\left(\mathrm{s}_{\mathrm{x}}-\mathrm{s}_{\mathrm{x}_{\text {tran }}}\right)+\mathrm{s}_{\mathrm{g}-\text { droptran }} \\
& \mathrm{V}_{\mathrm{g}-\mathrm{drop}}=\frac{-\mathrm{g}}{\left(\mathrm{n}_{\text {tran }}-2\right)\left(\frac{\mathrm{dV}}{\mathrm{ds}}\right)_{\operatorname{tran}}}\left[\left\{1+\mathrm{n}_{\text {tran }}\left(\frac{\mathrm{dV}}{\mathrm{ds}}\right)_{\operatorname{tran}} \frac{\left(\mathrm{s}_{\mathrm{x}}-\mathrm{s}_{\mathrm{x}_{\text {tran }}}\right)}{\mathrm{V}_{\text {tran }}}\right\}^{\frac{\mathrm{n}_{\text {tran }}-1}{\mathrm{n}_{\text {tran }}}}\right. \\
& \left.-\left\{1+\mathrm{n}_{\text {tran }}\left(\frac{\mathrm{dV}}{\mathrm{ds}}\right)_{\operatorname{tran}} \frac{\left(\mathrm{s}_{\mathrm{x}}-\mathrm{s}_{\mathrm{x}_{\text {tran }}}\right)}{\mathrm{V}_{\text {tran }}}\right\}^{\frac{1}{\mathrm{n}_{\text {tran }}}}\right] \\
& +\mathrm{V}_{\mathrm{g}-\mathrm{drop}_{\text {tran }}}\left\{1+\mathrm{n}_{\text {tran }}\left(\frac{\mathrm{dV}}{\mathrm{ds}}\right)_{\text {tran }} \frac{\left(\mathrm{s}_{\mathrm{x}}-\mathrm{s}_{\mathrm{x}_{\text {tran }}}\right)}{\mathrm{V}_{\text {tran }}}\right\}^{\frac{1}{\mathrm{n}_{\text {tran }}}} \mathrm{n} \neq 0,1,2 \\
& \mathrm{~s}_{\mathrm{g}-\mathrm{drop} \mathrm{sub}_{\text {sub }}}=\frac{-\mathrm{g}}{2\left(\mathrm{n}_{\text {tran }}-2\right)\left(\mathrm{n}_{\text {tran }}-1\right)\left(\frac{\mathrm{dV}}{\mathrm{ds}}\right)_{\text {tran }}^{2}}\left[\left\{1+\mathrm{n}_{\text {tran }}\left(\frac{\mathrm{dV}}{\mathrm{ds}}\right)_{\text {tran }} \frac{\left(\mathrm{s}_{\mathrm{x}_{\text {sub }}}-\mathrm{s}_{\mathrm{x}_{\text {tran }}}\right.}{\mathrm{V}_{\text {tran }}}\right\}^{\frac{2\left(\mathrm{n}_{\text {tran }}-1\right)}{\mathrm{n}_{\text {tran }}}}\right. \\
& \left.-1-2\left(\mathrm{n}_{\text {tran }}-1\right)\left(\frac{\mathrm{dV}}{\mathrm{ds}}\right)_{\operatorname{tran}} \frac{\left(\mathrm{s}_{\mathrm{x}_{\mathrm{sub}}}-\mathrm{s}_{\mathrm{x}_{\text {tran }}}\right)}{\mathrm{V}_{\text {tran }}}\right] \\
& +\frac{\mathrm{V}_{\mathrm{g}-\text { drop tran }}}{\mathrm{V}_{\text {tran }}}\left(\mathrm{s}_{\mathrm{x}_{\text {sub }}}-\mathrm{s}_{\mathrm{x}_{\text {tran }}}\right)+\mathrm{s}_{\mathrm{g}-\text { drop }_{\text {tran }}}
\end{aligned}
$$

Here the retardation at the transition point is determined from equation 38.

$$
\left(\frac{\mathrm{dV}}{\mathrm{ds}}\right)_{\text {tran }}=-\frac{1}{2 \mathrm{~m}} \rho \mathrm{V}_{\text {tran }} \mathrm{S}_{\text {ref }} \mathrm{C}_{\text {Dtransonic-upper }}
$$


Equation 38 allows for a discontinuity in the drag curve at the transition between supersonic and transonic flight. However, if the power-law representation of the drag in the supersonic regime provides a good representation of the drag coefficient at transition between supersonic and transonic, the drag coefficient at the transition Mach number can be evaluated using the supersonic power-law model, and the retardation at the transition Mach number can be obtained using the muzzle velocity, muzzle retardation, the supersonic power-law drag coefficient exponent, and the transition Mach number. This effectively eliminates the drag coefficient at the transition Mach number as an input parameter for the model.

$$
\left(\frac{\mathrm{dV}}{\mathrm{ds}}\right)_{\operatorname{tran}}=\left(\frac{\mathrm{V}_{\text {tran }}}{\mathrm{V}_{0}}\right)^{1-\mathrm{n}}\left(\frac{\mathrm{dV}}{\mathrm{ds}}\right)_{0}=\left(\frac{\mathrm{M}_{\text {tran }}}{\mathrm{M}_{0}}\right)^{1-\mathrm{n}}\left(\frac{\mathrm{dV}}{\mathrm{ds}}\right)_{0}
$$

\subsubsection{Transition Between Transonic and Subsonic Flight}

Once the projectile enters subsonic flight, equations 29-37 are no longer valid. The transonic to subsonic transition velocity is determined from the Mach number as shown in equation 40.

$$
\mathrm{V}_{\mathrm{sub}}=\mathrm{a}_{\infty} \mathrm{M}_{\mathrm{sub}}
$$

When equations 33-37 are used, the range, time of flight, gravity drop, and gravity drop velocity where the transition occurs between the transonic and subsonic flight can be determined.

$$
\begin{aligned}
& \mathrm{s}_{\mathrm{x}_{\text {sub }}}=\frac{1}{\left(\frac{\mathrm{dV}}{\mathrm{ds}}\right)_{\text {tran }} \frac{\mathrm{n}_{\text {tran }}}{\mathrm{V}_{\text {tran }}}}\left\{\left(\frac{\mathrm{V}_{\text {sub }}}{\mathrm{V}_{\text {tran }}}\right)^{\mathrm{n}_{\text {tran }}}-1\right\}+\mathrm{s}_{\mathrm{x}_{\text {tran }}} \\
& \mathrm{t}_{\text {sub }}=\frac{1}{\left(\mathrm{n}_{\text {tran }}-1\right)\left(\frac{\mathrm{dV}}{\mathrm{ds}}\right)_{\operatorname{tran}}}\left[\left\{1+\mathrm{n}_{\text {tran }}\left(\frac{\mathrm{dV}}{\mathrm{ds}}\right)_{\text {tran }} \frac{\left(\mathrm{s}_{\mathrm{x}_{\text {sub }}}-\mathrm{s}_{\mathrm{xtran}}\right)}{\mathrm{V}_{\text {tran }}}\right\}^{1-\frac{1}{\mathrm{n}_{\text {tran }}}}-1\right]+\mathrm{t}_{\text {tran }} \\
& \mathrm{s}_{\mathrm{g}-\mathrm{drop}_{\mathrm{sub}}}=\frac{-\mathrm{g}}{2\left(\mathrm{n}_{\text {tran }}-2\right)\left(\mathrm{n}_{\text {tran }}-1\right)\left(\frac{\mathrm{dV}}{\mathrm{ds}}\right)_{\text {tran }}^{2}}\left[\left\{1+\mathrm{n}_{\text {tran }}\left(\frac{\mathrm{dV}}{\mathrm{ds}}\right)_{\text {tran }} \frac{\left(\mathrm{s}_{\mathrm{x}_{\text {sub }}}-\mathrm{s}_{\mathrm{x}_{\text {tran }}}\right)}{\mathrm{V}_{\text {tran }}}\right\}^{\frac{2\left(\mathrm{n}_{\text {tran }}-1\right)}{\mathrm{n}_{\text {tran }}}}\right. \\
& \left.-1-2\left(\mathrm{n}_{\text {tran }}-1\right)\left(\frac{\mathrm{dV}}{\mathrm{ds}}\right)_{\operatorname{tran}} \frac{\left(\mathrm{s}_{\mathrm{x}_{\text {sub }}}-\mathrm{s}_{\mathrm{x}_{\text {tran }}}\right)}{\mathrm{V}_{\text {tran }}}\right] \\
& +\frac{\mathrm{V}_{\mathrm{g}-\text { droptran }}}{\mathrm{V}_{\text {tran }}}\left(\mathrm{s}_{\mathrm{x}_{\text {sub }}}-\mathrm{s}_{\mathrm{x}_{\text {tran }}}\right)+\mathrm{s}_{\mathrm{g}-\text { droptran }_{\text {tran }}}
\end{aligned}
$$




$$
\begin{aligned}
\mathrm{V}_{\mathrm{g}-\mathrm{drop} \text { sub }}=\frac{-\mathrm{g}}{\left(\mathrm{n}_{\text {tran }}-2\right)\left(\frac{\mathrm{dV}}{\mathrm{ds}}\right)_{\operatorname{tran}}}\left[\left\{1+\mathrm{n}_{\text {tran }}\left(\frac{\mathrm{dV}}{\mathrm{ds}}\right)_{\text {tran }} \frac{\left(\mathrm{s}_{\mathrm{x}_{\text {sub }}}-\mathrm{s}_{\mathrm{x}_{\text {tran }}}\right)}{\mathrm{V}_{\text {tran }}}\right\}^{\frac{\mathrm{n}_{\text {tran }}-1}{\mathrm{n}_{\text {tran }}}}\right. \\
\left.-\left\{1+\mathrm{n}_{\text {tran }}\left(\frac{\mathrm{dV}}{\mathrm{ds}}\right)_{\operatorname{tran}} \frac{\left(\mathrm{s}_{\mathrm{x}_{\text {sub }}}-\mathrm{s}_{\mathrm{x}_{\text {tran }}}\right)}{\mathrm{V}_{\text {tran }}}\right\}^{\frac{1}{\mathrm{n}_{\text {tran }}}}\right] \\
+\mathrm{V}_{\mathrm{g} \text {-drop } \operatorname{tran}}\left\{1+\mathrm{n}_{\text {tran }}\left(\frac{\mathrm{dV}}{\mathrm{ds}}\right)_{\text {tran }} \frac{\left(\mathrm{s}_{\mathrm{x}_{\text {sub }}}-\mathrm{s}_{\mathrm{x}_{\text {tran }}}\right)}{\mathrm{V}_{\text {tran }}}\right\}^{\frac{1}{\mathrm{n}_{\text {tran }}}} \mathrm{n} \neq 0,1,2
\end{aligned}
$$

\subsubsection{Trajectory Model for Subsonic Portion of Flight}

When equations 41-44 are used as initial conditions, the governing 3DOF equations can be integrated to determine the trajectory in the subsonic portion of flight. The solution has a similar form to the solution for the supersonic and transonic portions of flight as shown in equations 45-52.

$$
\begin{gathered}
\mathrm{V}_{\mathrm{x}}=\overline{\mathrm{V}} \cos \theta_{0} \\
\mathrm{~V}_{\mathrm{y}}=\overline{\mathrm{V}} \sin \theta_{0}+\mathrm{V}_{\mathrm{g}-\mathrm{drop}} \\
\mathrm{s}_{\mathrm{y}}=\mathrm{s}_{\mathrm{x}} \tan \theta_{0}+\mathrm{s}_{\mathrm{g}-\text { drop }} \\
\mathrm{s}_{\mathrm{z}}=\mathrm{w}_{\mathrm{z}}\left[\mathrm{t}-\frac{\mathrm{s}_{\mathrm{x}}}{\mathrm{V}_{0}}\right]
\end{gathered}
$$

where

$$
\begin{aligned}
& \overline{\mathrm{V}}=\mathrm{V}_{\text {sub }} \exp \left\{\left(\frac{\mathrm{dV}}{\mathrm{ds}}\right)_{\text {sub }} \frac{\left(\mathrm{s}_{\mathrm{x}}-\mathrm{s}_{\mathrm{xsub}}\right)}{\mathrm{V}_{\text {sub }}}\right\} \\
& \mathrm{t}=\mathrm{t}_{\mathrm{sub}}+\frac{1}{\left(\frac{\mathrm{dV}}{\mathrm{ds}}\right)_{\text {sub }}}\left[1-\exp \left\{-\left(\frac{\mathrm{dV}}{\mathrm{ds}}\right)_{\text {sub }} \frac{\left(\mathrm{s}_{\mathrm{x}}-\mathrm{s}_{\mathrm{xsub}}\right)}{\mathrm{V}_{\text {sub }}}\right\}\right] \\
& s_{\text {g-drop }}=\frac{-g}{4\left(\frac{d V}{d s}\right)_{\text {sub }}^{2}}\left(2\left(\frac{d V}{d s}\right)_{\text {sub }} \frac{\left(s_{x}-s_{\text {x sub }}\right)}{V_{\text {sub }}}+\exp \left\{-2\left(\frac{d V}{d s}\right)_{\text {sub }} \frac{\left(s_{x}-s_{\text {x sub }}\right)}{V_{\text {sub }}}\right\}-1\right) \\
& +\frac{\mathrm{V}_{\mathrm{g}-\text { drop }} \text { sub }}{\mathrm{V}_{\text {sub }}}\left(\mathrm{s}_{\mathrm{x}}-\mathrm{s}_{\mathrm{x} \text { sub }}\right)+\mathrm{s}_{\mathrm{g}-\text { drop }} \text { sub }
\end{aligned}
$$




$$
\begin{gathered}
\mathrm{V}_{\mathrm{g}-\mathrm{drop}}=\frac{-\mathrm{g}}{2\left(\frac{\mathrm{dV}}{\mathrm{ds}}\right)_{\text {sub }}}\left[\exp \left(\left(\frac{\mathrm{dV}}{\mathrm{ds}}\right)_{\text {sub }} \frac{\left(\mathrm{s}_{\mathrm{x}}-\mathrm{s}_{\mathrm{x}_{\text {sub }}}\right)}{\mathrm{V}_{\text {sub }}}\right)-\exp \left(-\left(\frac{\mathrm{dV}}{\mathrm{ds}}\right)_{\text {sub }} \frac{\left(\mathrm{s}_{\mathrm{x}}-\mathrm{s}_{\mathrm{x}_{\text {sub }}}\right)}{\mathrm{V}_{\text {sub }}}\right)\right] \\
+\mathrm{V}_{\mathrm{g} \text {-dropsub }} \exp \left(\left(\frac{\mathrm{dV}}{\mathrm{ds}}\right)_{\text {sub }} \frac{\left(\mathrm{s}_{\mathrm{x}}-\mathrm{s}_{\mathrm{x}_{\text {sub }}}\right)}{\mathrm{V}_{\text {sub }}}\right)
\end{gathered}
$$

Here the retardation at the transition point is determined from equation 53.

$$
\left(\frac{\mathrm{dV}}{\mathrm{ds}}\right)_{\text {sub }}=-\frac{1}{2 \mathrm{~m}} \rho \mathrm{V}_{\text {sub }} \mathrm{S}_{\text {ref }} \mathrm{C}_{\mathrm{D}_{\text {sub }}}
$$

Here $C_{D \text { sub }}$ is the drag coefficient in the subsonic regime.

\subsubsection{Extensions of the Method}

The method presented here addresses the transition from supersonic to transonic to subsonic flight as a specific application of the method. It should be noted that equations and methodology presented here could be easily adapted to address situations where the drag coefficient variation requires multiple piece-wise descriptions of the drag curve. For example, the equations in sections 2.2.2 and 2.2.3 could be applied directly to the case of supersonic flight where the drag coefficient is better described by two separate power-law variations. Such applications may result from the natural variation of the drag curve over a range of Mach numbers or perhaps from the transition between powered and glide phases of flight.

\section{Results}

The hybrid supersonic/transonic/subsonic trajectory model is applied here to the flight of a 9-mm pistol bullet that is launched at a supersonic velocity and reaches transonic or subsonic velocities later in flight. This application was addressed in reference 3 with the hybrid model that has an abrupt transition between supersonic and subsonic flight. The current model provides more fidelity in modeling the transonic regime.

Comparisons were also made with trajectory predictions made with the 4DOF model within Prodas (8) using an existing drag profile shown in figure 4 . Also shown in figure 4 is the drag variation used in the hybrid supersonic/transonic/subsonic power-law model. Table 1 shows the parameters used in the supersonic/transonic/subsonic model. These parameters were evaluated at standard atmospheric conditions. A transonic drag coefficient exponent of -5.4 was computed from the input parameters. 


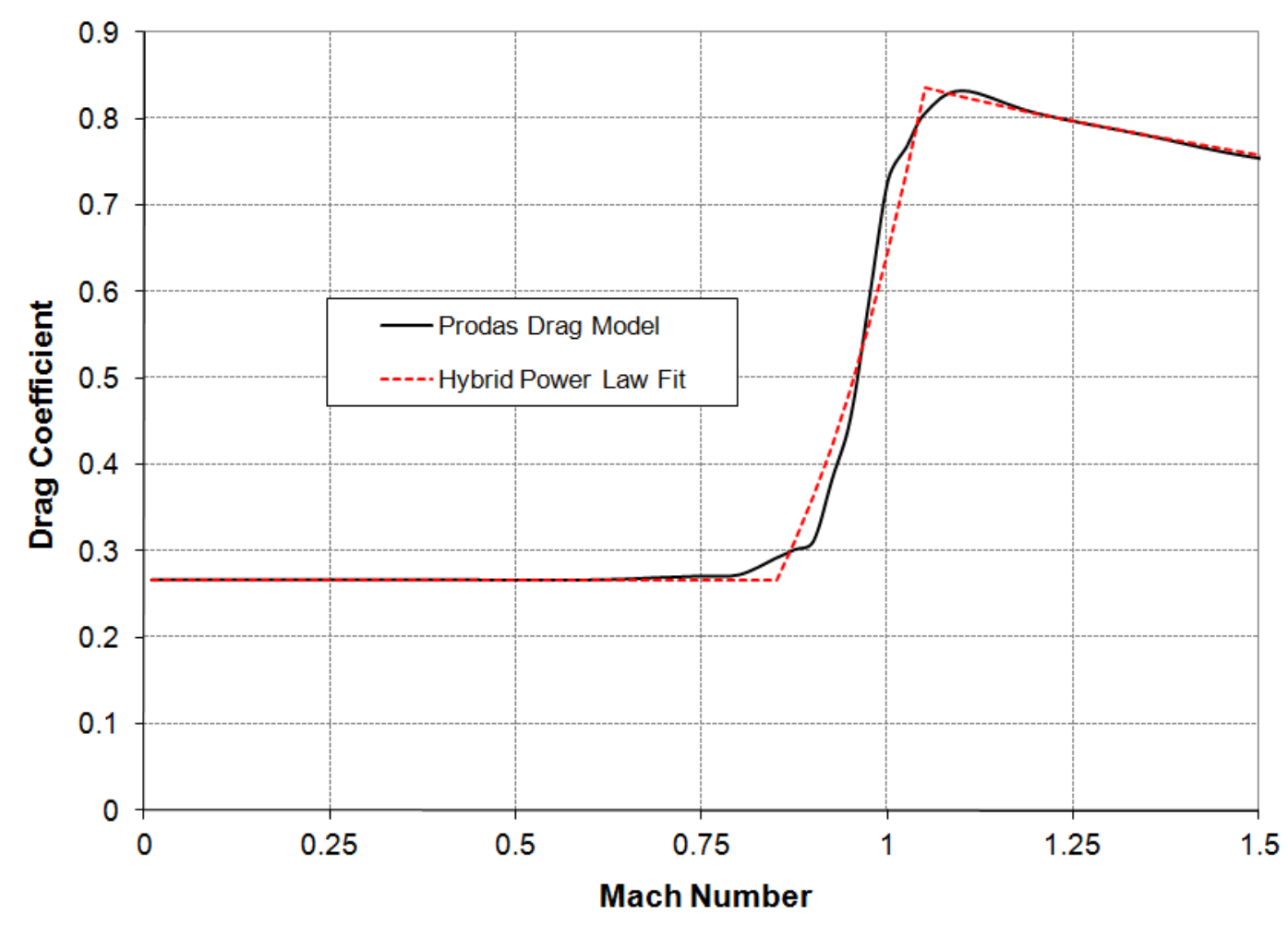

Figure 4. Drag coefficient as a function of Mach number: 9-mm pistol bullet.

Table 1. Parameters for 9-mm ball projectile used in hybrid supersonic/transonic/subsonic model.

\begin{tabular}{|l|c|}
\hline Muzzle velocity, $V_{0}$ & $416 \mathrm{~m} / \mathrm{s}$ \\
\hline Muzzle retardation, $\left(\frac{d V}{d s}\right)_{0}$ & $-1.74(\mathrm{~m} / \mathrm{s}) / \mathrm{m}$ \\
\hline Drag coefficient exponent, $\mathrm{n}$ & 0.27 \\
\hline Transition Mach number, $M_{\text {tran }}$ & 1.05 \\
\hline Subsonic Mach number, $M_{\text {sub }}$ & 0.85 \\
\hline Subsonic retardation at $M_{\text {tran }},\left(\frac{d V}{d s}\right)_{\text {sub }}$ & $0.4043(\mathrm{~m} / \mathrm{s}) / \mathrm{m}$ \\
\hline
\end{tabular}

Results are also presented here that were obtained previously using the hybrid supersonic/subsonic model (3). The parameters used for this model are shown in table 2. 
Table 2. Parameters for 9-mm ball projectile used in hybrid supersonic/subsonic model (3).

\begin{tabular}{|l|c|}
\hline Muzzle velocity, $V_{0}$ & $416 \mathrm{~m} / \mathrm{s}$ \\
\hline Muzzle retardation, $\left(\frac{d V}{d s}\right)_{0}$ & $-1.74(\mathrm{~m} / \mathrm{s}) / \mathrm{m}$ \\
\hline Drag coefficient exponent, $\mathrm{n}$ & 0.27 \\
\hline Transition (supersonic to subsonic) Mach number & 0.925 \\
\hline Subsonic retardation at transition Mach number & $-0.440(\mathrm{~m} / \mathrm{s}) / \mathrm{m}$ \\
\hline
\end{tabular}

Figure 5 shows the predicted velocity as a function of range obtained with the supersonic /transonic/subsonic model compared with Prodas predictions. Also shown are predictions using the supersonic power-law and the supersonic/subsonic power-law models. Each of the models shows excellent agreement from launch to the sonic velocity. It should be noted that for the current application, the results are relatively insensitive to the drag coefficient exponent (for the supersonic drag power-law) because the supersonic portion of flight is relatively short. The supersonic/transonic/subsonic model shows a gradual change in slope across the transonic regime that is nearly the same variation shown in the 4DOF Prodas predictions. The current model appears to provide a better representation of the velocity variation in the transonic regime than the supersonic/subsonic model, which shows an abrupt change in the velocity fall-off as the model transitions from the supersonic regime to the subsonic regime. The supersonic/transonic /subsonic model and the Prodas predictions show similar velocity variations in the subsonic regime where the drag coefficient is constant. 


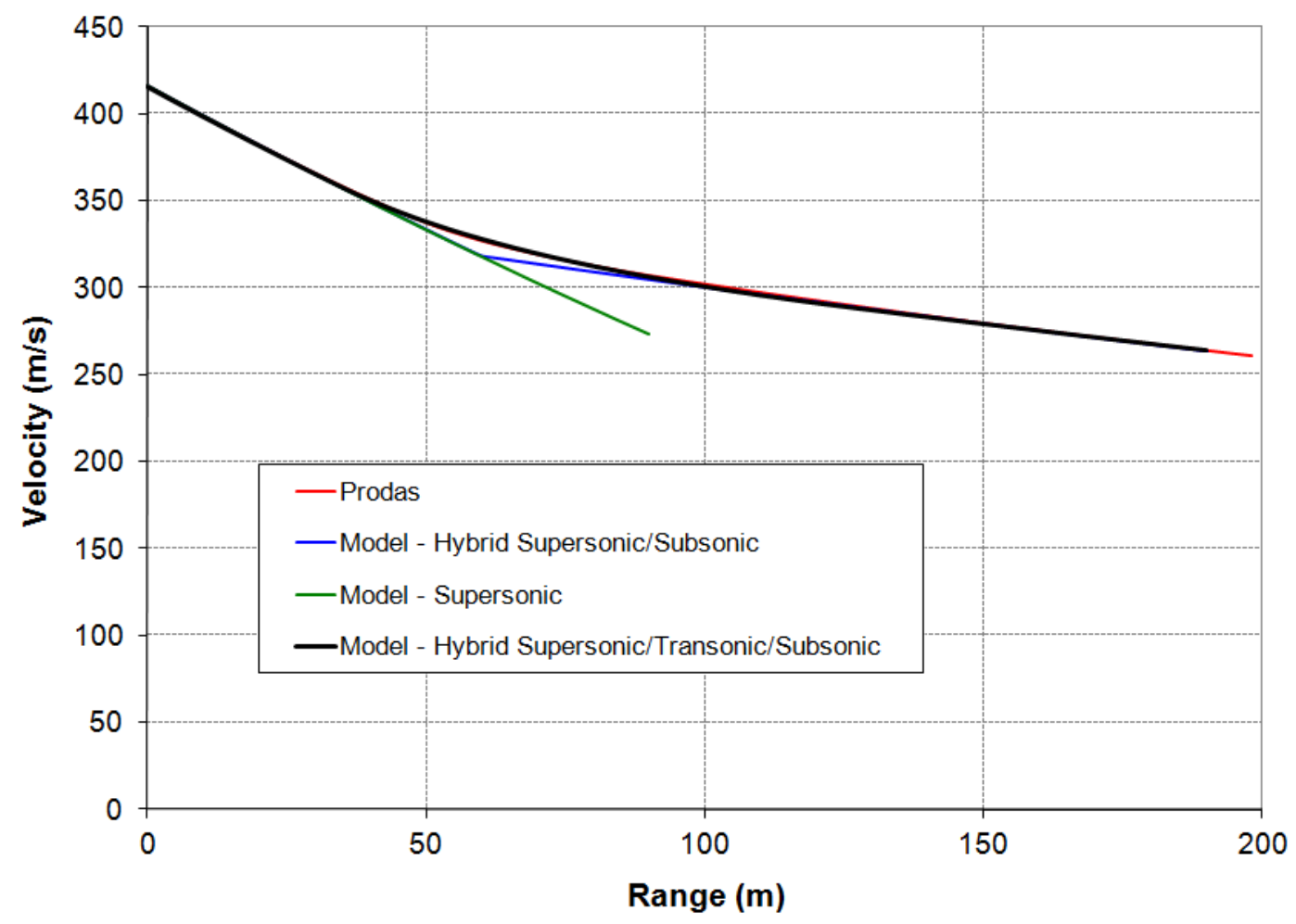

Figure 5. Velocity as a function of range: 9-mm pistol bullet.

Figures 6-9 show the predicted time of flight, the gravity drop, the wind drift, and gravity drop velocity as a function of range. The hybrid supersonic/transonic/subsonic model shows nearly the same variation with range as the Prodas predictions for these quantities. The hybrid supersonic/transonic/subsonic model eliminates the small discrepancies between the hybrid supersonic/subsonic model and the Prodas prediction that are due to the inability of the supersonic/subsonic model to account for the proper drag variation in the transonic regime. Compared with the velocity variation with range, these differences are somewhat less significant. 


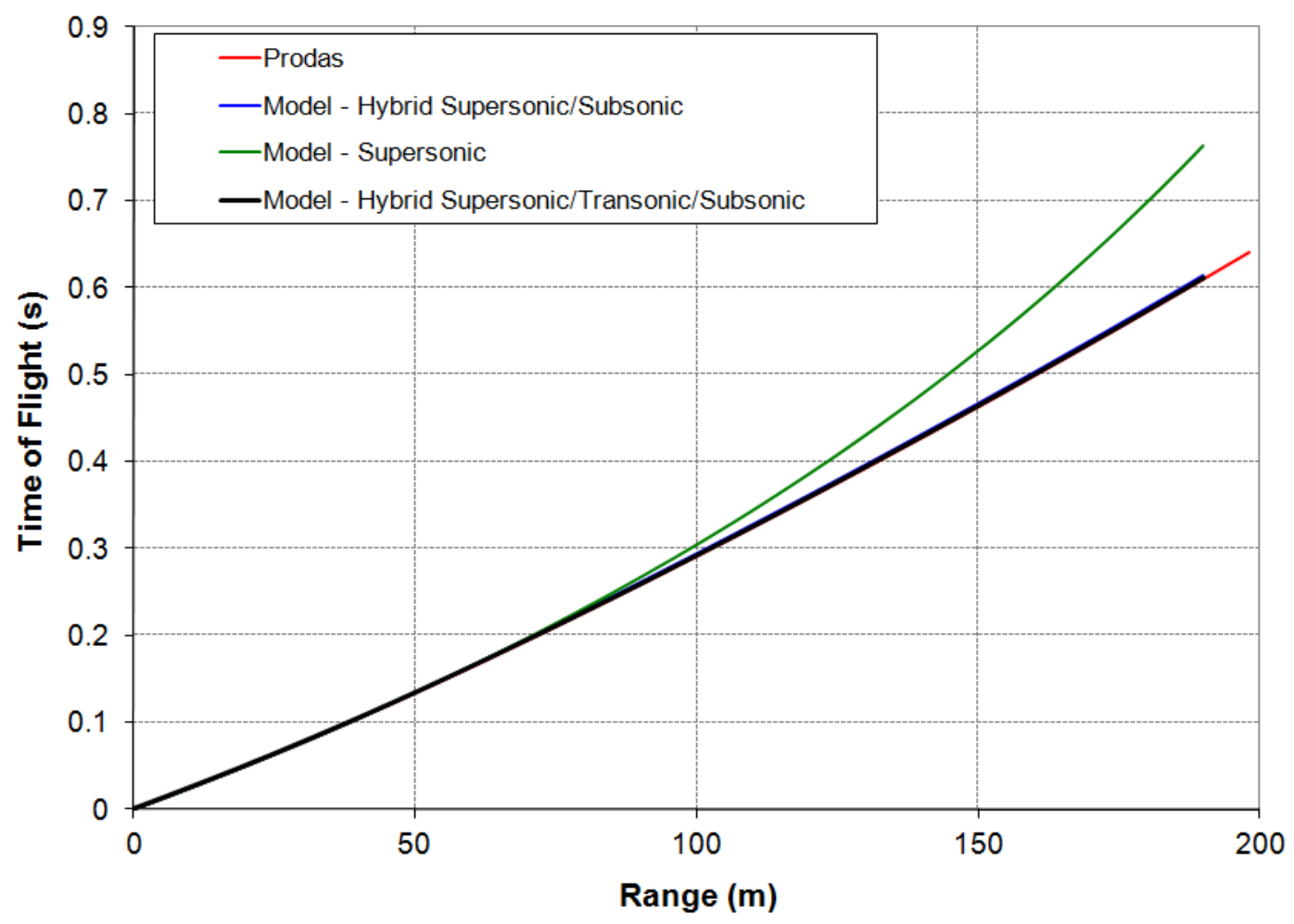

Figure 6. Time of flight vs. range: 9-mm pistol bullet.

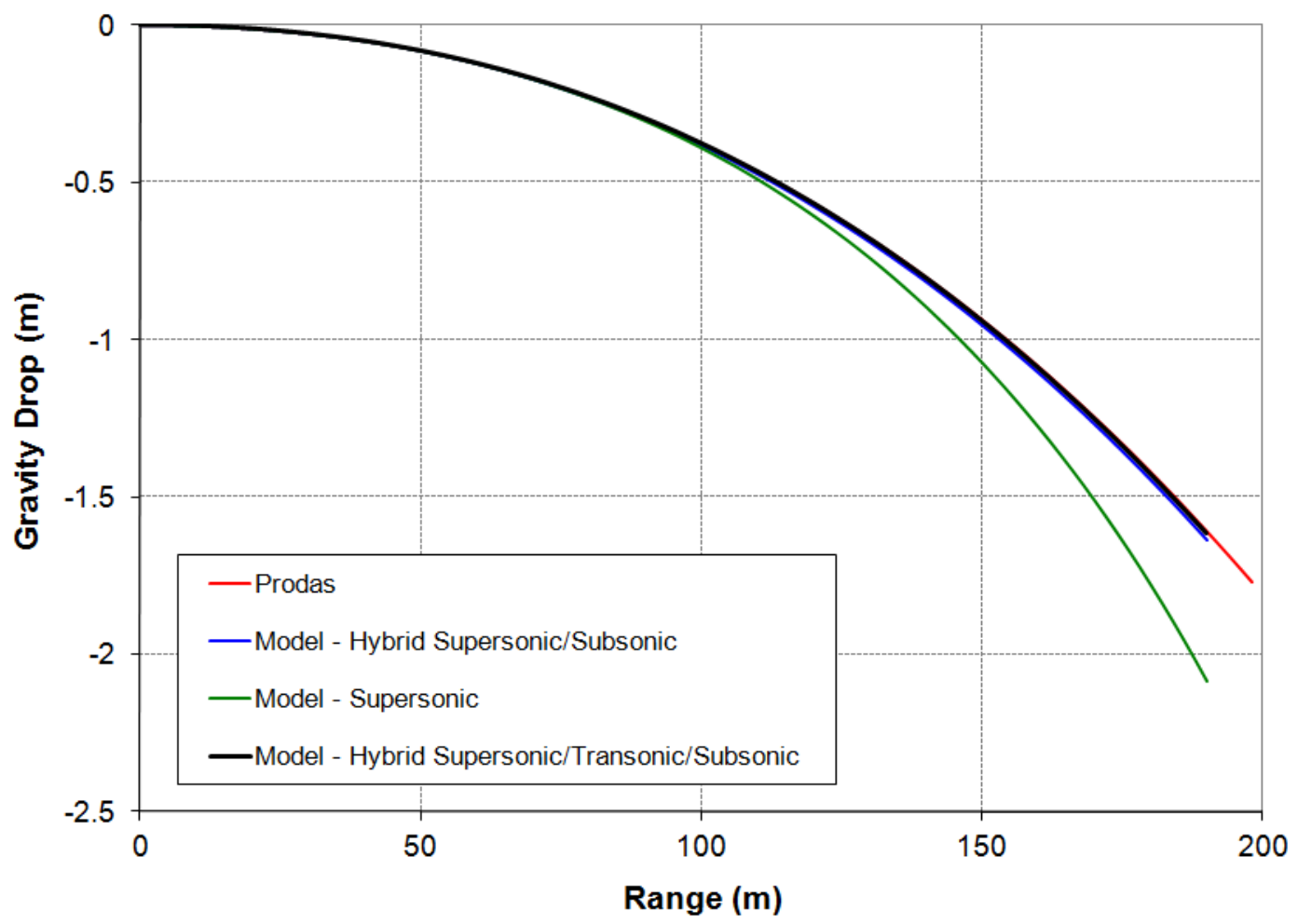

Figure 7. Gravity drop vs. range: 9-mm pistol bullet. 


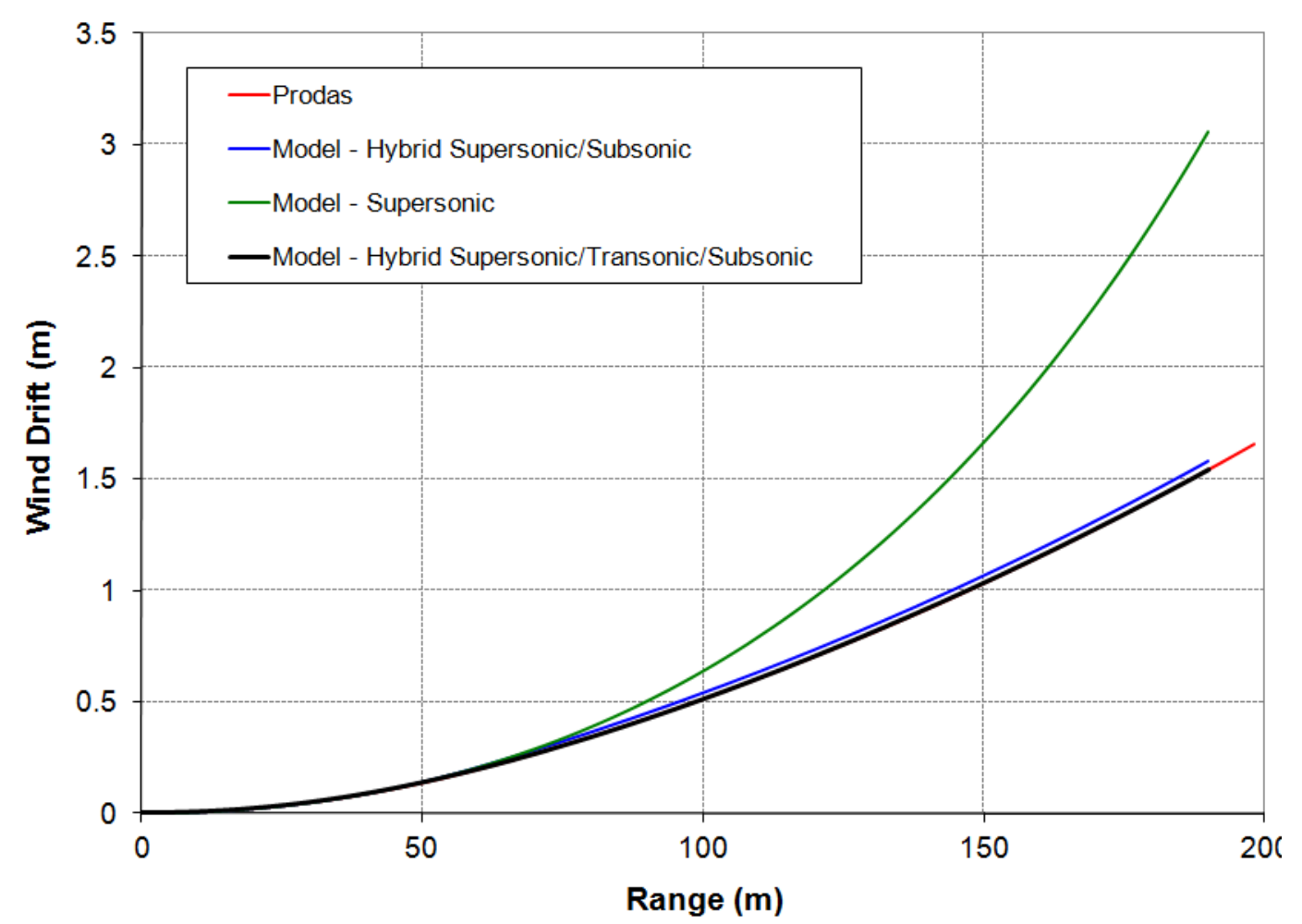

Figure 8 . Wind drift vs. range: 9-mm pistol bullet.

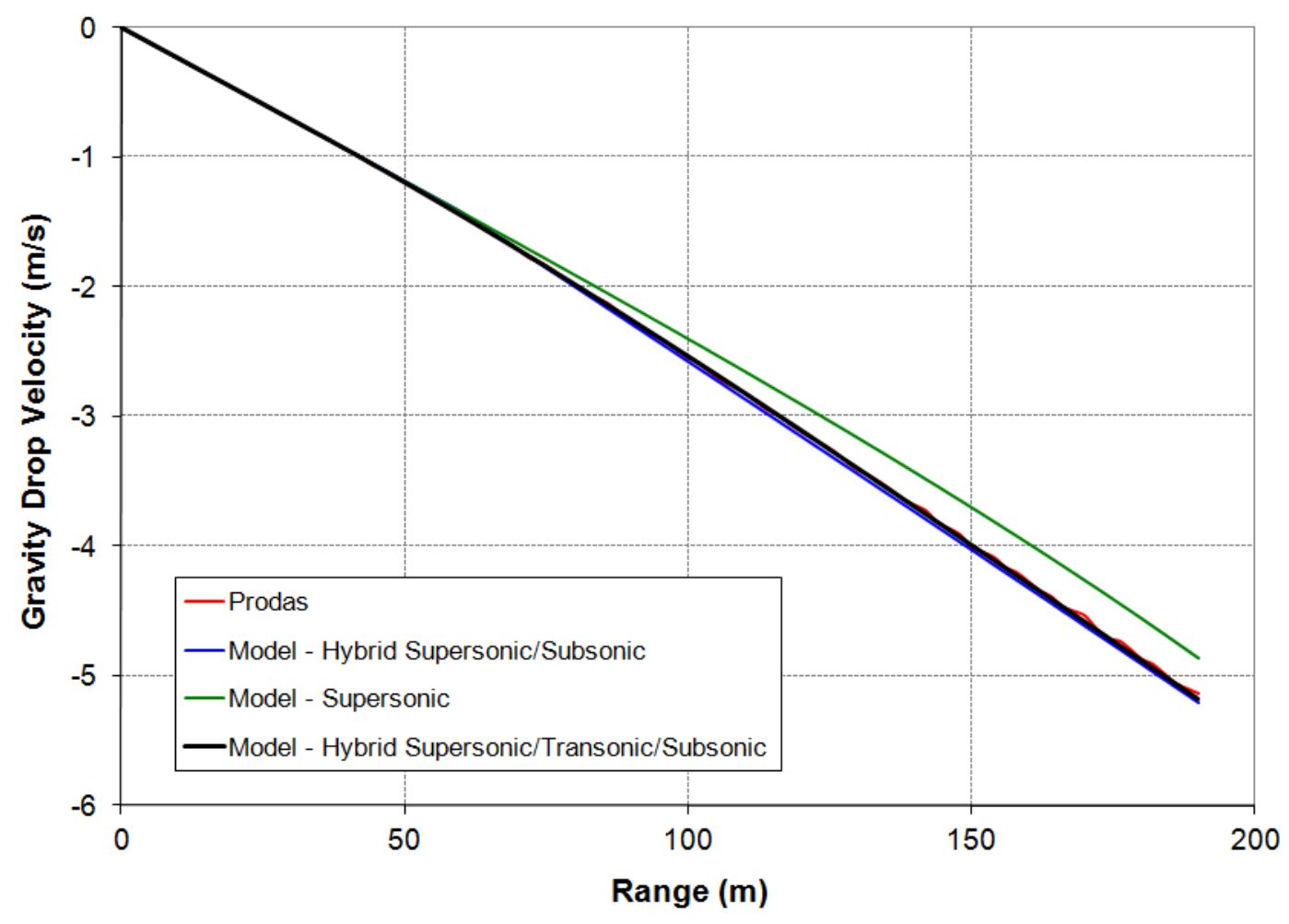

Figure 9. Gravity drop velocity vs. range: 9-mm pistol bullet. 
Provided that the supersonic and subsonic drag is adequately modeled with the power-law parameters, the most significant issue with the selection of input parameters for the current model concerns the span of the range regime (or alternatively the selection of transonic and subsonic Mach numbers $\mathrm{M}_{\text {tran }}$ and $\mathrm{M}_{\text {sub }}$ ). Figure 10 shows a drag coefficient model with three different power-law variations in the transonic regime. In addition to the baseline model (transonic regime between Mach 0.85 and Mach 1.05), two additional variations with narrower (Mach 0.925-0.975) and wider (Mach 0.8-1.1) variations are shown. The narrower and wider variations selected here represent a range of possible power-law models for the actual drag variation which cannot be modeled exactly with a power-law variation.

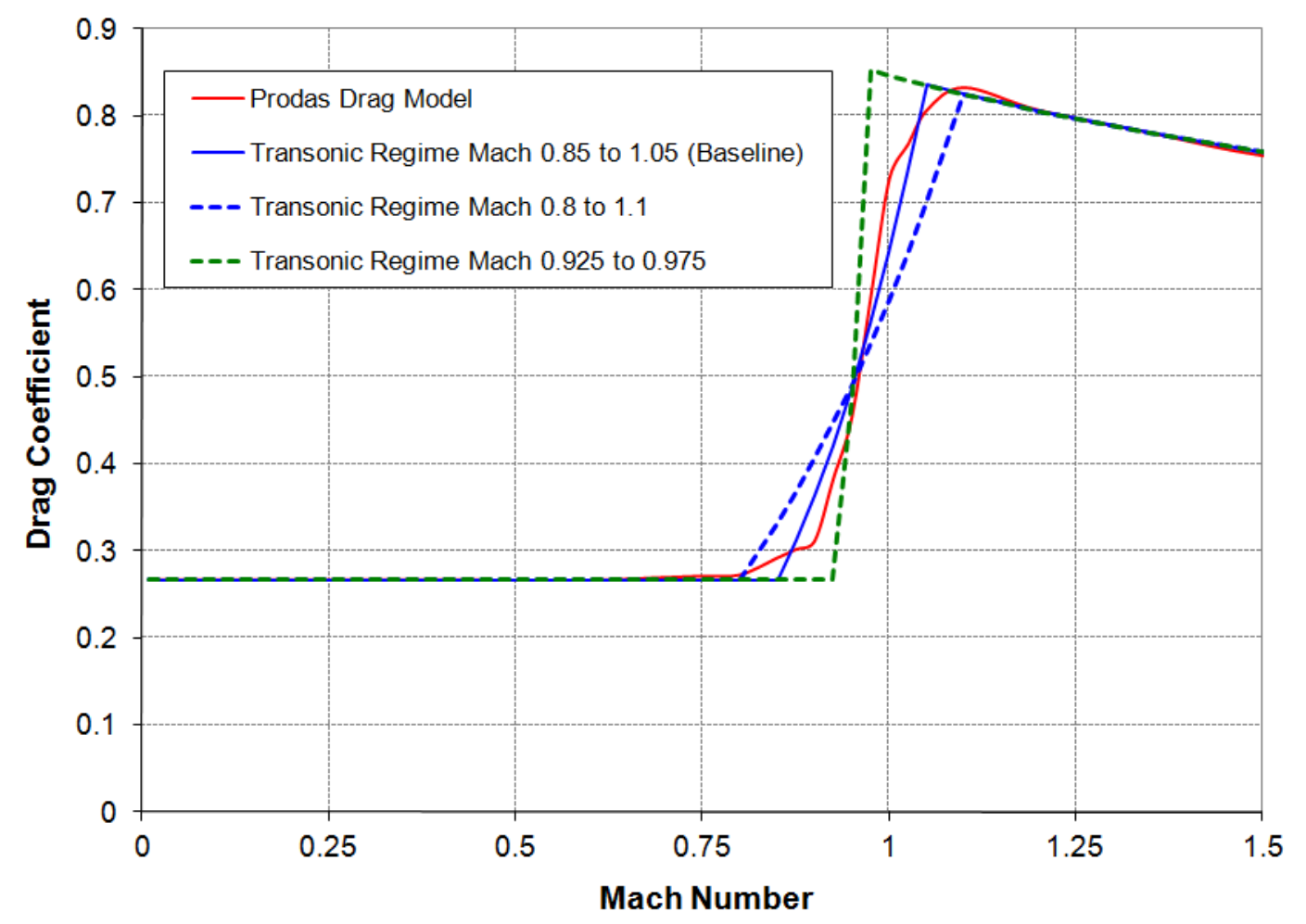

Figure 10. Modeling of drag coefficient as a function of Mach number with different power-law models.

Figures 11-14 show the predicted variation of the velocity, time of flight, gravity drop, and wind drift versus range for the three different power-law models. The predicted results show only minor differences between the predicted results using the various models and represent the range of uncertainty with the current model. Though not shown, results obtained with the span of the transonic regime between Mach 0.9 and 1.0 showed very little difference with the results obtained with the baseline model. 


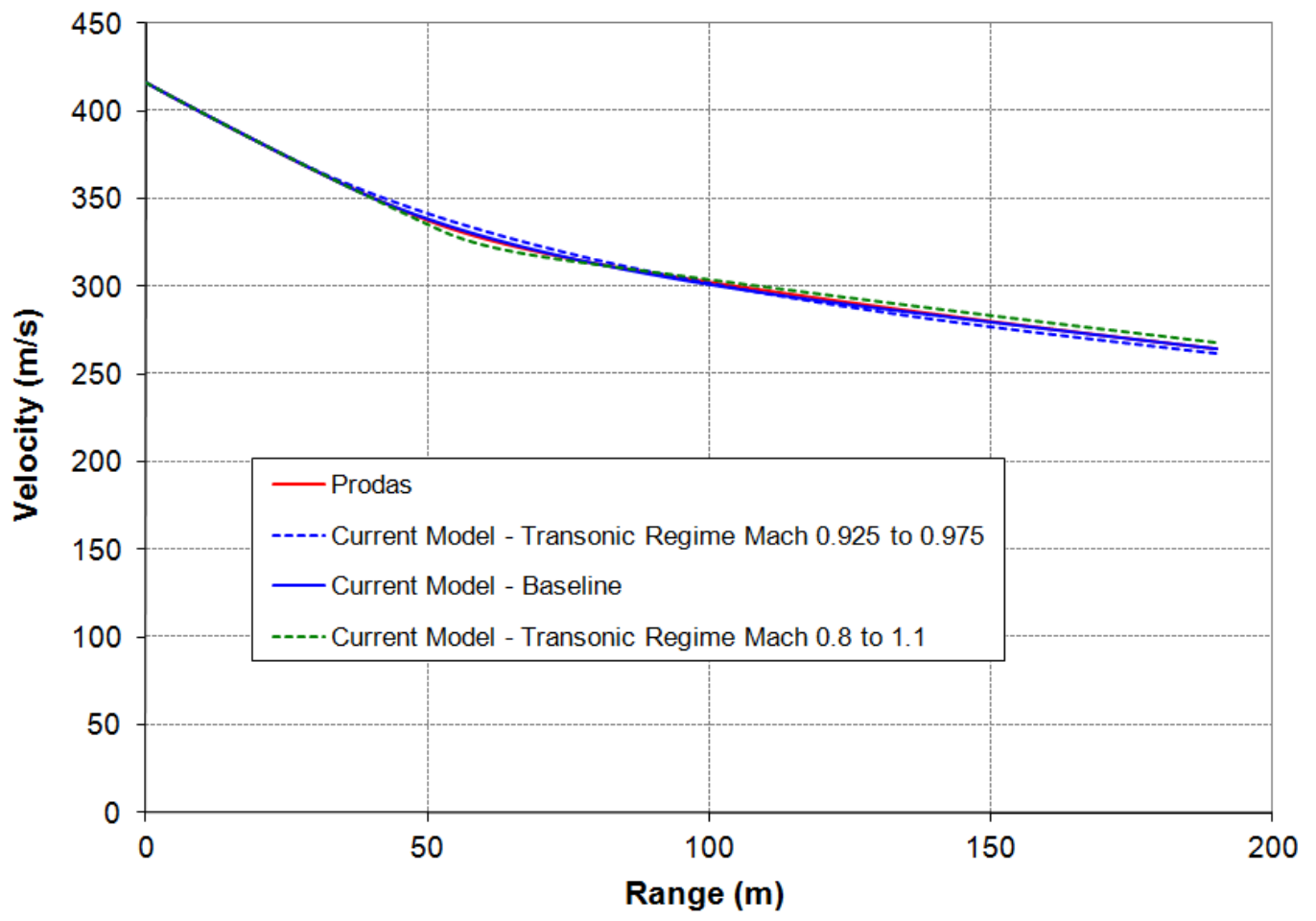

Figure 11. Sensitivity of velocity vs. range to selection of transonic power-law model: 9-mm pistol bullet.

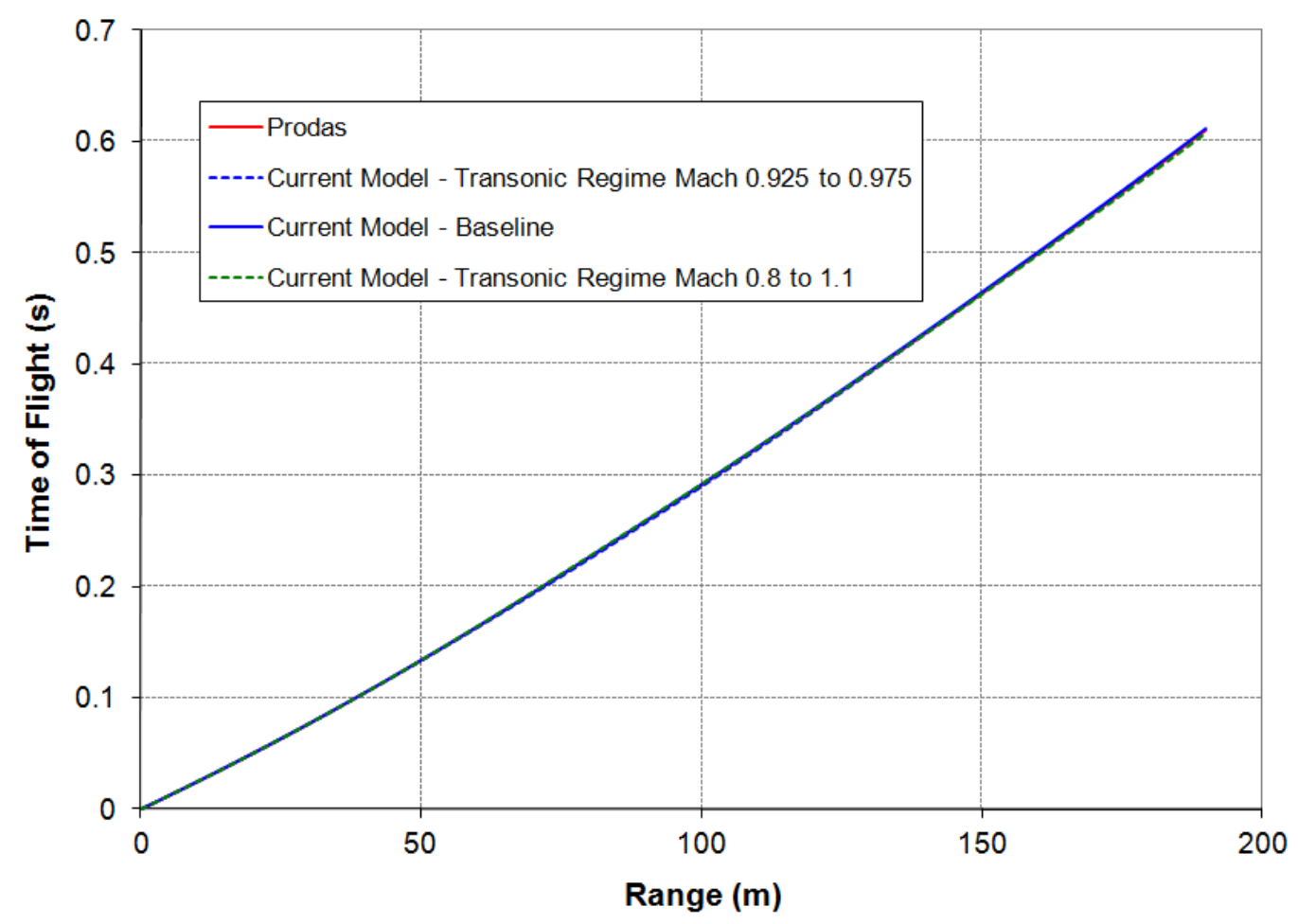

Figure 12. Sensitivity of time of flight vs. range to selection of transonic power-law model: 9-mm pistol bullet. 


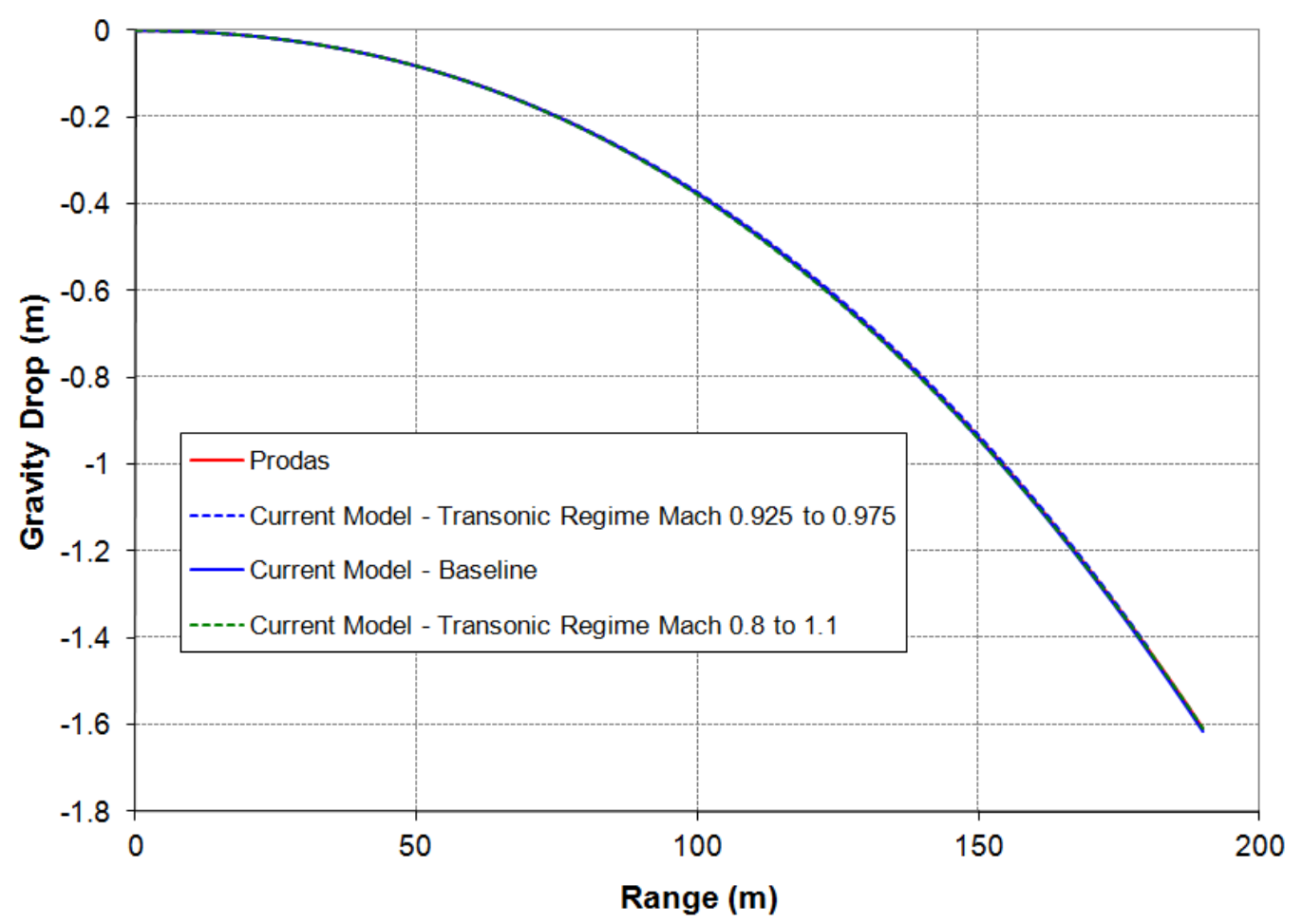

Figure 13. Sensitivity of gravity drop vs. range to selection of transonic power-law model: 9-mm pistol bullet.

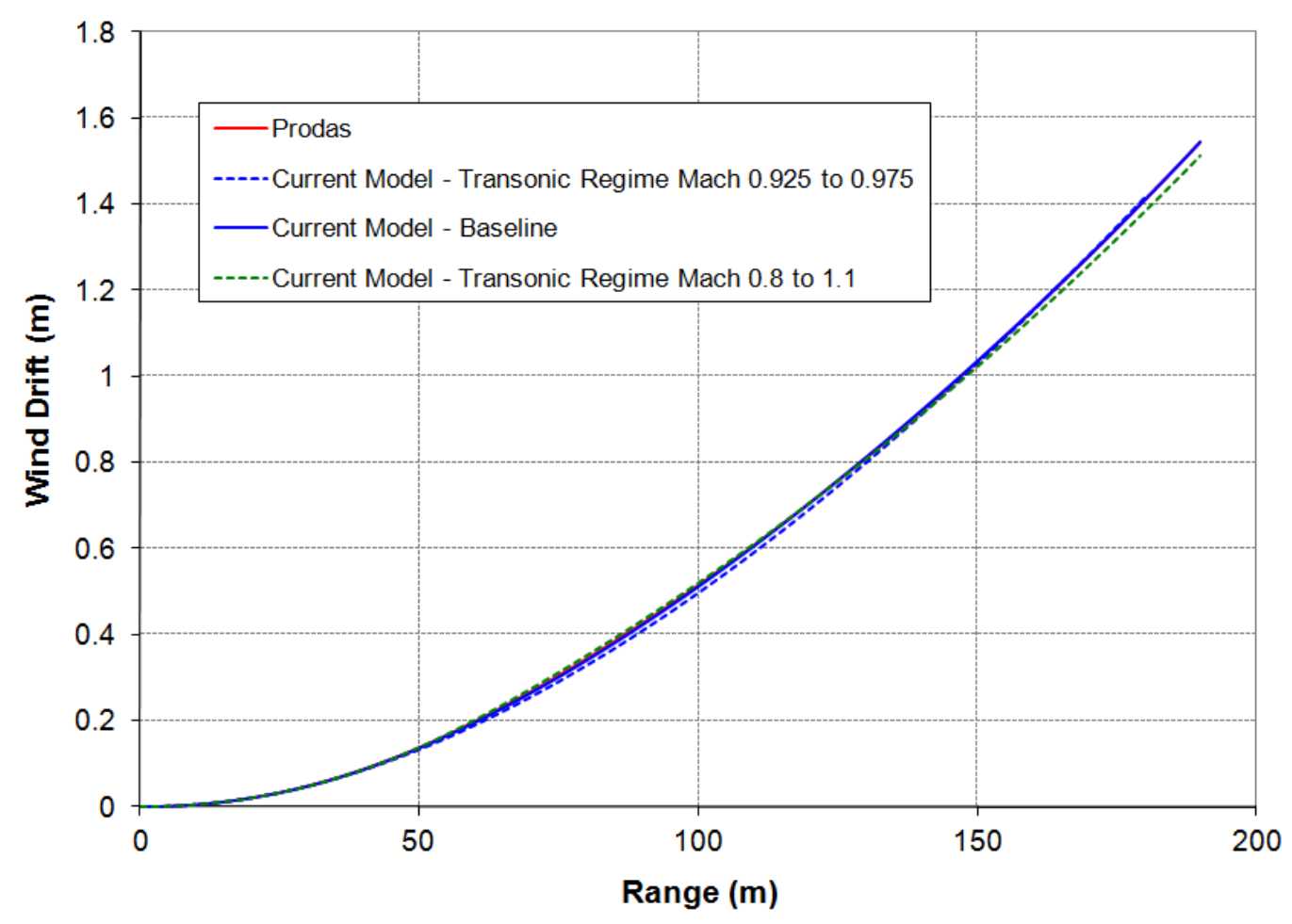

Figure 14. Sensitivity of wind drift vs. range to selection of transonic power-law model: 9-mm pistol bullet. 
Compared with the hybrid supersonic/subsonic model, which has an abrupt transition between the supersonic and subsonic regimes, the current model allows more direct modeling of the transonic drag variation and appears to require less user judgment (and resulting uncertainty) compared with the hybrid supersonic/subsonic model, which requires the selection of the single transition Mach number. However, the transonic drag behavior is often not completely characterized and therefore is a subject of some uncertainty itself. For many projectiles, the transonic regime may not be of significant enough interest to warrant complete characterization of the aerodynamics. Often, an assumed form for transonic drag rise is used, which introduces its own uncertainty in the trajectory prediction. As shown in the results presented here, this assumption may only produce minor differences in the predicted trajectory.

The selection of the hybrid supersonic/subsonic or the hybrid supersonic/transonic/subsonic model may be driven by the need to better define the variation of the predicted quantities within the transonic regime - most likely the velocity variation. As the results have shown, the current model provides an improved capability for doing that with only small overhead and additional inputs.

\section{Conclusions}

An approach for predicting the trajectory of projectiles with mixed supersonic, transonic, and subsonic flight is presented. The analysis presented shows that projectile flight with mixed supersonic, transonic, and subsonic flight regimes can be predicted with as few as six parameters: the muzzle velocity, the muzzle retardation, a power-law exponent that describes the shape of the drag curve in supersonic flight, the transition Mach number between the supersonic and transonic regimes, the transition Mach number between the transonic and subsonic portions of flight, and the subsonic retardation at the transition Mach number (or alternatively the subsonic drag coefficient). Closed-form expressions for the velocity, time of flight, gravity drop, and wind drift are developed to provide critical information about the trajectory of projectiles in direct-fire (low gun elevation angles). The current report extends previous work to incorporate modeling improvements when the details of the trajectory in the transonic regime are required. The method is simple, requires a minimum of input data, and allows rapid prediction of trajectory information across the complete span of supersonic, transonic, and subsonic flight.

The methodology and equations presented here are also easily adapted to address other situations where the drag coefficient variation requires multiple piece-wise descriptions of the drag curve. For example, the equations presented can be applied with little modification to the case of supersonic flight where the drag coefficient is better described by two separate power-law variations include applications where there is a natural variation of the drag curve over a range of Mach numbers or perhaps from the transition between powered and glide phases of flight. 


\section{References}

1. Weinacht, P.; Cooper, G. R.; Newill, J. F. Analytical Prediction of Trajectories for HighVelocity Direct-Fire Munitions; ARL-TR-3567; U.S. Army Research Laboratory: Aberdeen Proving Ground, MD, August 2005.

2. Weinacht, P.; Newill, J. F.; Conroy, P. J. Conceptual Design Approach for Small-Caliber Aeroballistics With Application to 5.56mm Ammunition; ARL-TR-3620; U.S. Army Research Laboratory: Aberdeen Proving Ground, MD, September 2005.

3. Weinacht, P. A. Hybrid Supersonic/Subsonic Trajectory Model for Direct Fire Applications; ARL-TR-5574; U.S. Army Research Laboratory: Aberdeen Proving Ground, MD, June 2011.

4. McCoy, R. L. Modern Exterior Ballistics; Schiffer Military History: Atglen, PA, 1999.

5. Tilghman, B. A. M855 Aeropack Data, Firing Tables Branch; U.S. Army Armament RD\&E Center, Aberdeen Proving Ground, MD, 8 December 2003.

6. McCoy, R. L. Aerodynamic and Flight Dynamic Characteristics of the New Family of 5.56mm NATO Ammunition; BRL-MR-3476; U.S. Army Ballistics Research Laboratory: Aberdeen Proving Ground, MD, October 1985.

7. McCoy, R. L. The Effect of Wind on Flat-Fire Trajectories; BRL Report No. 1900; U.S. Army Research Laboratory: Aberdeen Proving Ground, MD, August 1976.

8. Arrow Tech Associates. Prodas Users Manual; Burlington, VT, 2002. 


\section{Nomenclature}

\begin{tabular}{|c|c|}
\hline$a_{\infty}$ & free-stream speed of sound \\
\hline $\mathrm{C}_{\mathrm{D}}$ & drag coefficient \\
\hline$\left.\mathrm{C}_{\mathrm{D}}\right|_{\mathrm{V}_{0}}$ & drag coefficient evaluated at the muzzle velocity \\
\hline $\mathrm{C}_{\mathrm{D}_{\text {sub }}}$ & drag coefficient in the subsonic regime \\
\hline $\mathrm{C}_{\mathrm{D}_{\text {transonic-lower }}}$ & drag coefficient evaluated at the lower end of the transonic regime \\
\hline $\mathrm{C}_{\mathrm{D}_{\text {transonic-upper }}}$ & drag coefficient evaluated at the upper end of the transonic regime \\
\hline $\mathrm{D}$ & reference diameter \\
\hline $\mathrm{g}$ & gravitational acceleration \\
\hline $\mathrm{m}$ & projectile mass \\
\hline M & Mach number \\
\hline $\mathrm{M}_{0}$ & Mach number at muzzle \\
\hline $\mathrm{M}_{\mathrm{sub}}$ & Mach number at transition between transonic and subsonic flight \\
\hline $\mathrm{M}_{\text {tran }}$ & Mach number at transition between supersonic and transonic flight \\
\hline $\mathrm{n}$ & $\begin{array}{l}\text { exponent defining the variation of the drag coefficient with Mach number in the } \\
\text { supersonic regime }\end{array}$ \\
\hline $\mathrm{n}_{\text {tran }}$ & $\begin{array}{l}\text { exponent defining the variation of the drag coefficient with Mach number in the } \\
\text { transonic regime }\end{array}$ \\
\hline s & total downrange displacement \\
\hline $\mathrm{S}_{\mathrm{g}-\mathrm{drop}}$ & gravity drop \\
\hline $\mathrm{S}_{\mathrm{g}-\mathrm{drop}} \mathrm{sub}_{\mathrm{n}}$ & gravity drop evaluated at the transition between transonic and subsonic flight \\
\hline $\mathrm{S}_{\mathrm{g}-\mathrm{drop}}$ tran & gravity drop evaluated at the transition between supersonic and subsonic flight \\
\hline $\mathrm{S}_{\mathrm{x}}, \mathrm{s}_{\mathrm{y}}$ & horizontal and vertical displacement along trajectory \\
\hline
\end{tabular}




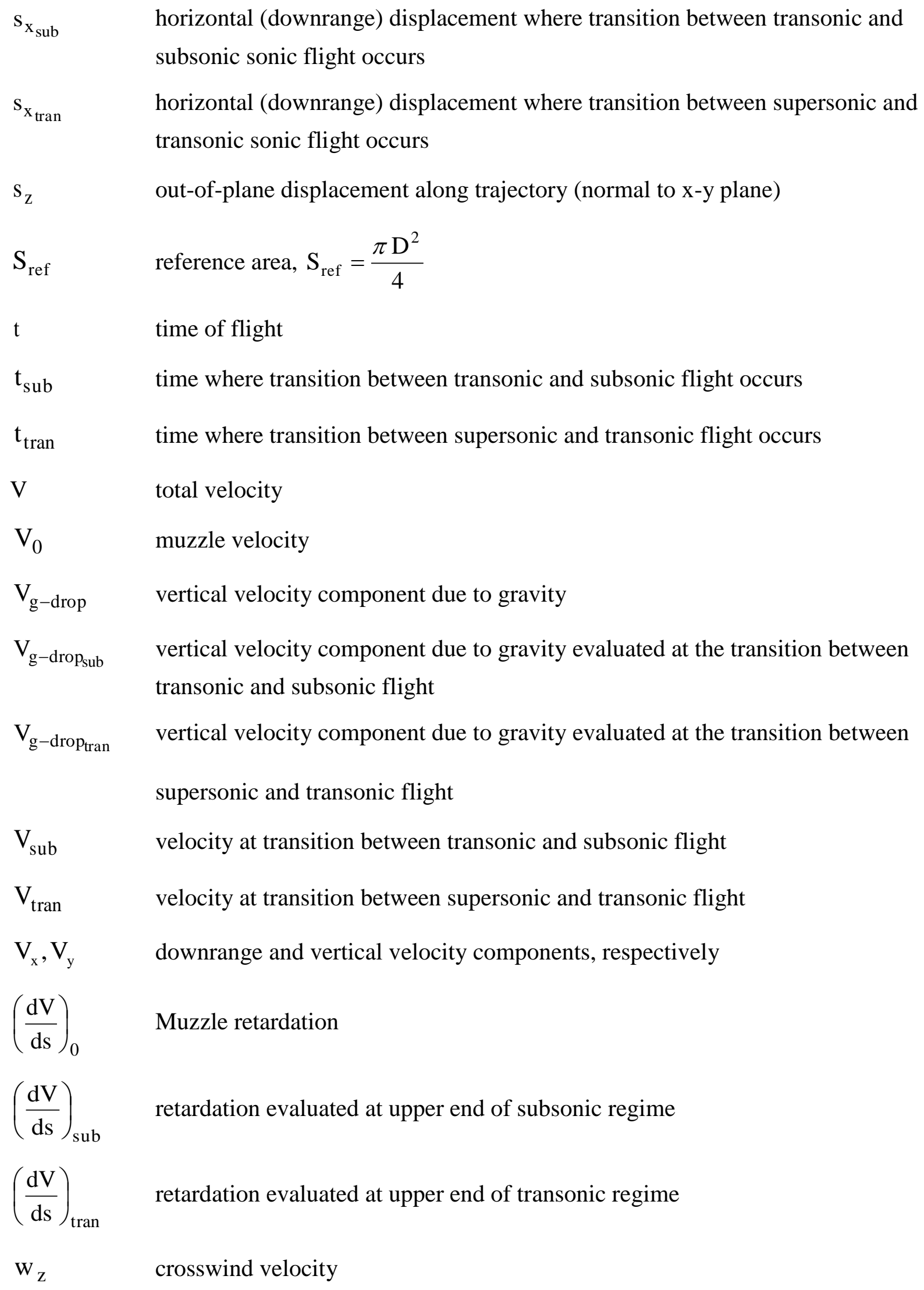


$\underline{\text { Greek Symbols }}$

$\begin{array}{ll}\theta_{0} & \text { initial gun elevation angle } \\ \rho & \text { atmospheric density }\end{array}$




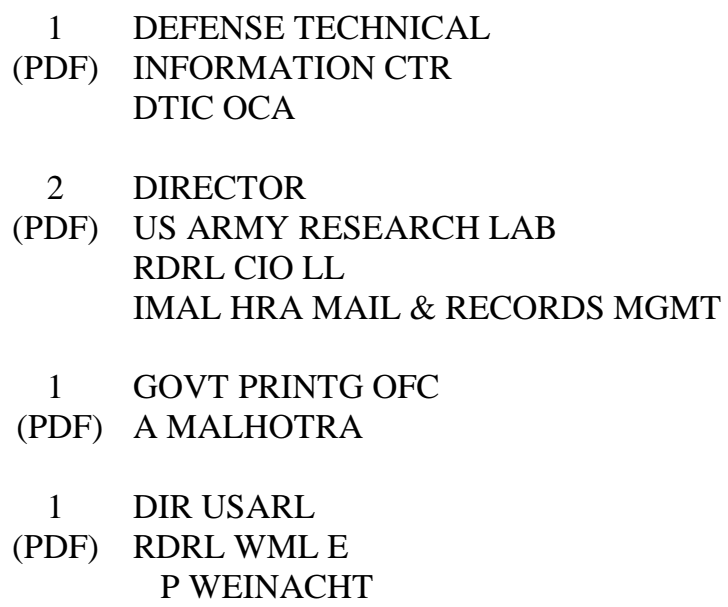

